\title{
Determinants of the Choice of Job Search Channels by the Unemployed Using a Multivariate Probit Model
}

\author{
Chiara Mussida ${ }^{1} \cdot$ Luca Zanin $^{2}$ (D)
}

Accepted: 6 July 2020 / Published online: 17 July 2020

(c) Springer Nature B.V. 2020

\begin{abstract}
We investigate factors affecting the job search channels (newspapers, agency, informal network, direct contact, internet) of unemployed individuals in Italy using a multivariate probit model. We separately analyse unemployed individuals who lost their job or who are entering the labour market for the first time (i.e., with or without previous job experience, respectively). We use cross-sectional microdata covering the 2014-2018 period. We do not find important differences in the determinants in common between unemployed individuals with and without previous job experience (such as, age, education, and citizenship). The main difference between the two samples is in the composition, with more young people in the latter group (mainly individuals in the school-to-work transition) than in the first one. We find that better-educated unemployed people have more of a multichannel attitude when searching for jobs than their counterparts. Moreover, for unemployed individuals with previous job experience, the characteristics of their last job play a crucial role in influencing the choice of search channel(s). For example, unemployed individuals from highskilled professions (that typically require the employment of better-educated individuals) choose the internet with a higher probability than other channels, while those from lowskilled professions and with experience in manufacturing have a higher probability of considering employment agencies than those in qualified professions in commercial activities and services. We have assumed that the unobservable factors affecting the decision process of a multichannel job search (estimated through the pairwise correlation coefficients across the residuals of the models) are represented by personality features of an individual, such as motivation, self-control, and preferences. A strong, positive, and significant correlation is found between job searching through the internet and direct contact with firms, but with some spatial differences between macro-areas of the country.
\end{abstract}

Keywords Job search behaviour · Multivariate probit model $\cdot$ Multichannel attitude Unemployed with and without previous job experience

Luca Zanin

luca.zanin@studio.unibo.it

Chiara Mussida

chiara.mussida@unicatt.it

1 Department of Economic and Social Sciences, Università Cattolica del Sacro Cuore, via Emilia Parmense 84, 29122 Piacenza, Italy

2 Prometeia, Piazza Trento e Trieste 3, 40137 Bologna, Italy 
JEL Classification C30 $\cdot$ J24 $\cdot$ J64

\section{Introduction}

Recent official statistics on the Italian labour market show that each year, about three million individuals search for a job because they are unemployed. ${ }^{1}$ Figure 1 shows that 10 years after the economic and financial crisis of 2008-2009, the cyclical component of unemployment is slightly reduced, while the structural component still remains very high. ${ }^{2}$

The structural component of unemployment is a critical issue that affects not only Italy but also other European countries such as Spain and Greece (Azmat et al. 2006; Blanchard and Jimeno 1995; de la Rica and Rebollo-Sanz 2015), although with some differences (e.g. Baussola and Mussida 2017; Murtin and Robin 2018). Long-term unemployment is a multidimensional construct that is affected by aspects that intersect (a) rules of macroeconomics and the policy agendas of governments with (b) rules of microeconomics and behavioural economics, including aspects of sociology and psychology. As regards (a), Italy is characterised by a number of problems that have been dragging on for a long time and include a high public debt, low productivity, a poor welfare system to balance work and private life, and other issues. Such elements of fragility contribute to making the intersection between labour demand and supply difficult by accentuating long-term unemployment, especially in the southern regions of Italy (e.g. Cracolici et al. 2009; Zanin and Calabrese 2017; Barbieri and Mussida 2018). The matter of unemployment has not only economic costs but also social costs that relate strongly to unemployment duration (Ochsen and Welsch 2011). These include aspects of (b), for which a number of studies have demonstrated that people who lose their job and who have difficulty finding a new one may manifest depressive symptoms and anxiety (e.g. Vansteenkiste et al. 2004 and references therein) and are unsatisfied with their quality of life (e.g. Zanin 2013, 2016). These negative states associated with (long-term) unemployment may lead people into a spiral of pessimism, with negative effects on their job search motivation. Among issues related to (b), at the root of the difficulty of finding a job are not only the skill-job mismatches or spatial mismatches, for which a wide literature is available (e.g. Adams et al. 2000; Brueckner and Zenou 2003; Gimbel and Sinclair 2020), but also possible mismatches between the job search channel(s) an unemployed person has decided to use and firms' decisions regarding which channel(s) to open job vacancies on. Increasing knowledge of the issue may help to explain some aspects of the behaviour of job searching by the unemployed. This may offer support to guide firms that aim to hire employees (for instance, in the process of placement of the announcements for job vacancies) as well as for policymakers to design effective support services for job search guidance. In this regard, firms and policymakers might be interested to know (1) how the unemployed look for a job through a variety of job search

\footnotetext{
1 We are referring to unemployed individuals between 15 and 74 years of age who had carried out at least one active job search action in the thirty days preceding the interview and were available to work within the 2 weeks following the interview (ILO 1982).

2 The cyclical component increased with the crisis and is reducing with economic recovery, while the structural component is due to causes that go beyond the economic cycle. For instance, the structural component may be due to spatial differences in the productive system, the mismatch between the skills workers can offer the labour market and the skills demanded by employers, technological change, and the institutional setting (see also Barbieri and Mussida 2018). The reduction of the structural component can take time to be solved and represents one of the main challenges for policymakers.
} 


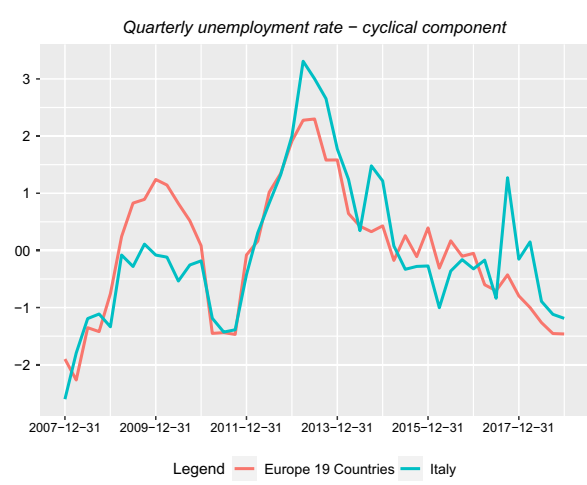

(a)

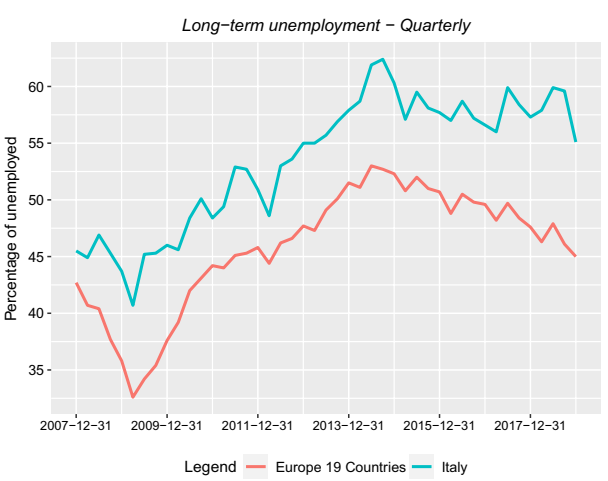

(b)

Fig. 1 The data on unemployment rates and long-term unemployment were obtained from the Eurostat database. We extracted the cyclical component of the unemployment rate using the alternative approach to the Hodrick-Prescott filter proposed by Hamilton (2018) and applied it using the R package neverhpfilter

channels; (2) how they are characterised; and (3) what the differences are between unemployed individuals with and without previous job experience (if any).

Our aim is to shed light on these matters by using microdata from the Labour Force Survey (LFS) collected by the Italian National Institute of Statistics (ISTAT) for the 2014-2018 period. The issue of how firms announce job vacancies and what is (or what are) the most successful job search channel(s) for the unemployed goes beyond the scope of this study and deserves specific investigation. To answer point (iii), our empirical analyses were carried out distinguishing between unemployed individuals with and without previous job experience.

Firstly, following the literature in the field (e.g. Della Vigna and Paserman 2005; Bachmann and Baumgarten 2013), we explore the determinants of the number of channels used by unemployed individuals for job searches (as a proxy of the degree of diversification and a multichannel attitude) by estimating a Poisson regression. As a limit of this analysis, however, we are not able to detect the features underlying the choice of each channel as well as the possible dependence structure between the job search channels. We thereby specify a multivariate probit model that allows taking into account observable variables (e.g. socio-demographics) and unobservables (e.g., motivation, self-control, and preference, which are hardly measurable and not measured in the survey used). Specifically, the impacts of unobservables are estimated through the correlated error structure among utility functions of the different search channels. In the literature, it has been demonstrated how aspects of the personality sphere may be an integral part of the decisional process in many domains of life, including the decisional process in job search behaviour (see, e.g., Della Vigna and Paserman 2005; Zikic and Saks 2009; Tso et al. 2010; Constant et al. 2011; Baay et al. 2014; van Huizen and Plantenga 2014; Klehe and van Hooft 2018).

To the best of our knowledge, until now, scholars have explored the features of single channels using univariate probit or logit models (e.g. Blau and Robins 1990; Addison and Portugal 2002; Labini 2005; Bachmann and Baumgarten 2013) or using bivariate models looking jointly at formal and informal job search channels (e.g. van den Berg and van der Klaauw 2006). Modelling simultaneously two or more binary outcomes conditional on some covariates can overcome some limits of univariate models when multiple 
related relationships are studied. Such modelling frameworks have found applications in many fields of the literature such as the social sciences (e.g. Zanin et al. 2013; Zanin 2015; Acosta-Ballesteros et al. 2018), the labour market (e.g. Radice et al. 2013; Gai et al. 2017; Mussida and Zanin 2020), household economics (e.g. Zanin 2017, 2018a, b), risk management (e.g. Calabrese et al. 2019), medicine (e.g. Winkelmann 2012; EspasandínDomínguez et al. 2019), management science (e.g. Torugsa et al. 2019), and transportation (e.g. Becker et al. 2017).

The rest of the article proceeds as follows. In Sect. 2, we review the literature on job search channels. Section 3 describes the microdata used for the econometric analysis. Section 4 introduces the model representation and estimation, and Sect. 5 presents the results of the empirical analysis. Concluding remarks are offered in Sect. 6.

\section{Literature Review}

From the job-matching literature we know that in equilibrium, unemployment rates crucially depend on the efficiency of the process of how unemployed individuals (job-seeking individuals) are matched with open job vacancies (e.g. Barron et al. 1989; Pissarides 2000). Usually, this matching process is treated as a black box (Petrongolo and Pissarides 2001). However, individuals can influence the efficiency of the process by deciding their job search effort, the time invested in their job search, as well as the typology or mix of search channels to use (e.g. Bachmann and Baumgarten 2013).

Job search theory suggests that unemployed individuals should choose their search methods by comparing the expected returns/benefits and costs associated with the available alternatives. Benefits are mainly in the form of job offers, which may vary in their typology, quantity, and quality by affecting the probability of being employed and the income earned in the next period. Costs may be of a pecuniary nature or related to time and effort (see, for instance, Holzer 1988; Blau and Robins 1990). More recent literature also pinpoints the role of individual characteristics in affecting the choice of search methods (e.g. Weber and Mahringer 2008).

In this strand of job search theory, one of the earlier studies of the determinants of the choice of job search methods and their effectiveness is Holzer (1988). He analysed a sample of unemployed youths and found that the main determinants of the choice of search channel are the relative costs in terms of time spent on a particular channel for generating job offers and their acceptance. In the same strand, Blau and Robins (1990) analyse job search choices and outcomes by investigating the differences between the search methods of unemployed and employed individuals. They find that the choice of channel is based on a cost/benefit analysis and that, in general, the job search is less costly for the employed than for the unemployed. In a more recent work that enlarges the view of job search theory, Weber and Mahringer (2008) provide evidence that the success of a search method is not only based on a cost/benefit comparison but is also highly heterogeneous across individual characteristics such as education and labour market attachment.

In addition to the factors or determinants affecting the choice of search methods and their effectiveness, the typology of job search channels and their mix play a prominent role in the efficiency of the matching process (Mortensen and Vishwanath 1995; Caliendo et al. 2011). Understanding their evolution through time is therefore important for planning effective policies aimed at alleviating the issues associated with (long-term) unemployment. 
On the typology of job search channels, a specific strand of the literature has focused on how unemployed people search for a job through and within their relationship networks by using weak ties (that is, less familiar contacts) and/or strong ties (that is, family and friends). The seminal work of Granovetter (1973) argued that weak ties are more important to finding employment than strong ties because weak ties should provide non-redundant or novel information of relevance to job-seekers. According to Granovetter (1973), the idea follows from the fact that on average, weak ties are less likely to overlap with strong ties since weak ties know a smaller fraction of one's other family members or friends with respect to strong ties. Less overlap in family relationships and friends increases the range of the social network available to each individual. Therefore, individuals with relatively low/less overlap in such relationships should have more individuals in their social network and therefore more (possible) opportunities to obtain information about a job. However, since the 1980s several researchers have contested Granovetter, and it has been commonly argued that strong ties are more important in helping unemployed people find jobs because family and friends are generally more present in the lives of the unemployed than are other contacts (e.g. Cappellari and Tatsiramos 2010, 2015; Kramarz and Nordstrom Skans 2014; Ramia et al. 2020). Further studies on job searching also considered not only informal networks (Putnam 2000; Pichler and Wallace 2007) but also formal networks such as newspapers and magazine advertisements, public competition or direct contact, the internet, and employment service agencies (Pichler and Wallace 2007; Ingold and Valizade 2017; Liechti 2019).

The evolution of the use and effectiveness of informal and formal channels has been widely investigated as well. For instance, van den Berg and van der Klaauw (2006) analyse the effect of counselling and monitoring active labour market policies (to stimulate reemployment of the unemployed) on a number of formal and informal job search channels. Their results suggest that counselling and monitoring stimulate the use of formal search methods at the expense of informal methods. They also find that formal channels are more likely to be used by older individuals than younger ones. In addition, they note how the substitution, from informal to formal, is strongest for individuals with the best labour market opportunities. Caliendo et al. (2011) analyse instead the role of social networks in the job search choices of unemployed individuals. Their investigation is based on the hypothesis that individuals with wider networks of relationships should experience higher productivity from their informal search channels. This, in turn, affects not only the choice of formal search channels but also the reservation wage. The importance of informal networks over formal ones is also confirmed by other empirical studies of European countries (see Bewley 1999; Ioannides and Loury 2004).

The literature on job search channels in Italy is relatively scarce, offers mixed evidence, and is particularly focused on the use of informal channels by the employed and unemployed. Pistaferri (1999) analyses the effect of informal networks on individuals' job searches and earnings by using data from the 1991 and 1993 Bank of Italy Survey of Household Income and Wealth. Results suggest that, despite the fact that seeking work through informal networks (that is, through friends, relatives, or acquaintances of potential employers) increases the probability of receiving job offers, the use of informal channels is also associated with lower earnings than formal channels.

Mosca and Pastore (2009) examine the effectiveness of job search methods in the Italian social service sector. Their findings suggest that non-profit organizations prefer informal recruitment methods to better select the most motivated workers. Pellizzari (2010) primarily explores the wage effect (wage premiums and/or wage penalties) of finding jobs through informal channels by using data from the European Community Household Panel. The 
evidence is mixed across European countries, and it varies with the efficiency of formal job search channels. In particular, for Italy, he also investigates the effect of the first labour market reform (the Treu package) that liberalized the provision of employment services (formal channels) in 1998. ${ }^{3}$ Interesting results emerged regarding the effect by macro-area. Prior to the reform, the wage effects of using informal channels in the north and the south of Italy were not statistically different and were associated with a wage penalty. After 1998, no significant change occurred in the south, whereas in the north the wage effect reversed to being positive and significant. This evidence suggests that the wage premium for finding jobs through informal contacts is higher in countries where the presence of professional recruiters is more relevant. In addition, Ponzo and Scoppa (2010) provide evidence on informal job searches in the Italian system. They focus on employees in the private sector and try to explain the factors determining the probability of using informal channels and their impact on the quality of job matches. Their findings suggest that informal channels are predominant in Italy and are used frequently by individuals with low levels of education, who work in small firms or low-productivity firms, and who live in highunemployment regions (mainly southern Italy). Moreover, they note that informal channels do not always lead to efficient job matches. A proportion of workers hired through informal networks seems characterised by lower productivity, probably because they are poorly educated and low-skilled. Meliciani and Radicchia (2011) instead analyse the consequences of being recruited through formal and/or informal channels, using data collected through a survey implemented by the Institute for the Development of the Vocational Training of Workers (ISFOL). They find that the unemployed entering the labour market via formal channels enjoy a wage bonus and a reduction in entry times, while those recruited via informal channels save on entry times but receive, on average, relatively lower wages (as confirmed in other studies). Moreover, the use of the informal channel seems to characterise individuals with less interest or lower attitudes toward lifelong learning, or the overeducated who have not found a match in line with their skills (see also Perez-Gonzalez 2006; Bandiera et al. 2007; Kramarz and Nordstrom Skans 2007).

\section{Data}

The analysis is based on cross-sectional microdata (named 'micro.STAT') from the Labour Force Survey (LFS) collected by the Italian National Institute of Statistics. The survey collects information on the main aggregates of the labour market (job search, employment status, work experience, and so on), allowing us to carry out an analysis that is broken down by socio-demographic characteristics and territorial factors. ISTAT provides microdata on the labour market starting from 1977. However, over the years, the LFS has undergone important changes in terms of the structure of the information collected with the questionnaire, the definition of the main aggregates of the labour market, and the structure of the sample (see "Appendix 2"). These changes would require us to reconstruct and homogenise the quarterly microdata for comparability. This is an effort that has already been partially carried out by ISTAT for the reconstruction of some historical series of the main labour market aggregates. For our analyses, however, some issues of discontinuity or partial

\footnotetext{
3 The Treu package (law 196/1997) was passed in December 1997. The authors explore its effect by using a difference-in-differences analysis.
} 
availability of information still remain. We have therefore decided to restrict the econometric analysis to the 2014-2018 period. The analysis of such a period allows defining the unemployed according to the most recent official definition (see footnote 1 in the introductory section), allows homogeneity in the structure of the information used for the econometric analysis, and enables the analysis to be easily extended by using the most recent quarterly 'micro.STAT' data freely downloadable from the ISTAT website. ${ }^{4}$ The 'micro. STAT' of the LFS are available from the first quarter of 2014. The 'micro.STAT' data from the LFS are available from the first quarter of 2014.

According to the methodological note provided by ISTAT $^{5}$ the sampling design adopted in each quarter is a two-stage design with stratification of the first-stage units. The firststage units are the municipalities, and the second-stage units are families. Each quarterly survey is based on a monthly type of time stratification. Specifically, the quarterly sample of final sampling units (families) is divided into three distinct groups, each of which is randomly assigned to a month of the quarter so that each of the three groups constitutes a representative sample of the reference population in the month considered. The population of interest is made up of all members of families residing in Italy, even if they have temporarily emigrated abroad, while it excludes the permanent members of cohabitation institutions (hospices, religious institutes, barracks, etc.).

The analysis focuses on unemployed individuals from 15 to 74 years of age with and without previous job experience and who are not looking for self-employment opportunities. The information on the job experience of unemployed individuals is collected by the LFS through a specific question asking for the presence or absence of previous job experience. Over the 2014-2018 period, we consider samples of 18,892 and 55,120 unemployed individuals with and without previous job experience, respectively.

\subsection{The Job-Search Channels}

The effort with which an unemployed individual looks for their first job or a new job has typically been explored using different proxy variables. Some scholars have considered the number of applications in a determined time period (e.g. Van der Klaauw and Van Vuuren 2010), the amount of time invested in the job search (e.g. Krueger and Mueller 2010), or the number of search channels or methods (e.g. Della Vigna and Paserman 2005; Bachmann and Baumgarten 2013).

Table 7 summarises the modalities or main channels an unemployed individual can consider when searching for a job. For a more effective exploratory analysis, we have collapsed them into five (macro-)search channels. Specifically, the list is as follows: newspaper and magazine advertisements (newspaper); network of relatives and friends (informal network); public competition or direct contact (direct contact); the internet; and employment agencies (public or private). Further details on the items included in each macrochannel are provided in Table 7 of "Appendix 1". We construct five binary variables, each of which takes the value of 1 if the unemployed individual used the k-th channel, and zero otherwise. This allow us to trace the possible choice of multiple job search channels. The sum of the number of channels considered by each unemployed individual can be considered as a synthetic measure of the diversification of the job search (in our case, the measure

\footnotetext{
${ }^{4}$ https://www.istat.it/it/archivio127792.

${ }^{5}$ https://www.istat.it/microdata/download.php?id=/import/fs/pub/wwwarmida/2/2014/1/Nota.pdf.
} 
Table 1 Descriptive statistics of the samples of unemployed individuals with and without previous job experience for the period of 2014-2018

Variables

Unemployed without Unemployed

previous job experience with previous job

experience

Multichannel attitude

Average number of job-search channels

Job search channels

Newspapers

44.19

44.33

Informal network

86.27

88.54

Direct contact

78.63

74.83

Internet

65.19

57.29

Agency (public or private)

31.82

39.96

Socio-demographic characteristics

Male

55.95

Age range

15-24

25-34

35.56

26.39

$35-44$

11.42

28.34

45-54

5.50

25.58

$55-64$

1.28

10.27

65-74

0.04

0.44

Education

Primary education

6.60

Lower secondary education

38.70

49.00

Upper education

41.66

34.53

Tertiary education

15.45

9.87

Citizenship

Italian

88.30

From European Union

Extra-European Union

Marital status

Single

45.01

Married

Separated or divorced

Widowed

Main characteristics of previous job

0.56

Agriculture

Manufacturing

Construction

Trade

Type of employment

Employee

Collaboration agreement 
Table 1 (continued)

\begin{tabular}{lll}
\hline Variables & $\begin{array}{l}\text { Unemployed without } \\
\text { previous job experience }\end{array}$ & $\begin{array}{l}\text { Unemployed } \\
\text { with previous job } \\
\text { experience }\end{array}$ \\
\hline Occupation & & \\
$\quad$ Legislator, entrepreneur, manager & & 0.91 \\
Intellectual, scientific, and high-specialisation professions & & 9.17 \\
Technical professions & & 10.18 \\
Office worker & & 9.68 \\
Qualified professions in commercial activities and services & & 27.83 \\
Craftsmen, specialised workers, and farmers & & 18.00 \\
Fixed and mobile machinery workers and vehicle drivers & & 6.68 \\
Non-qualified professions & & 17.34 \\
Armed forces & & 0.21 \\
Duration of job search & & \\
From 0 to 3 months & 9.53 & 16.55 \\
From 4 to 6 months & 7.53 & 10.97 \\
From 7 to 12 months & 20.06 & 18.97 \\
More than 12 months & 62.88 & 53.51 \\
Spatial variable & & \\
Northwest & 14.65 & 22.38 \\
Northeast & 8.07 & 13.57 \\
Centre & 15.21 & 20.08 \\
Southern Italy & 43.24 & 28.28 \\
Main islands & 18.83 & 15.69 \\
Sample period & $2014-2018$ & \\
Observations & 18,892 & 55,120 \\
\hline & &
\end{tabular}

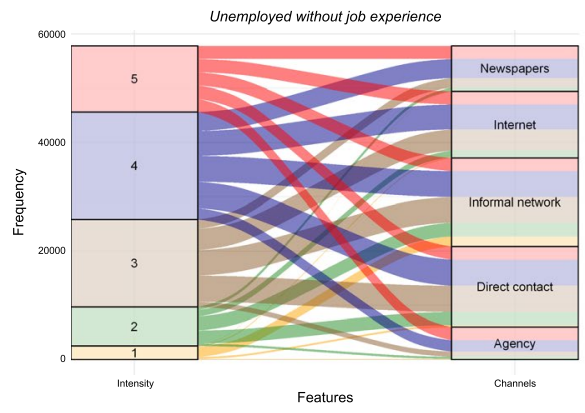

(a)

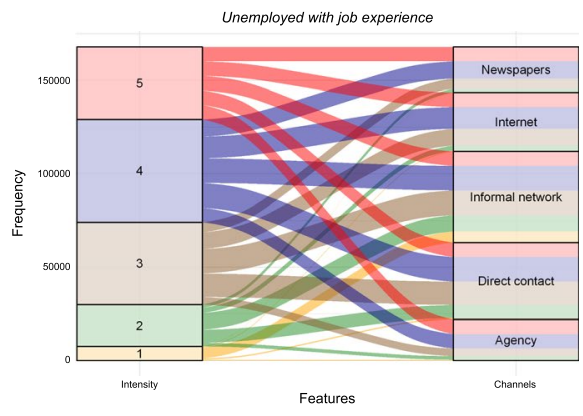

(b)

Fig. 2 The composition of the multichannel attitude for unemployed individuals with and without previous job experience

ranges from 1 to 5). In other words, the higher the number of (macro-)channels explored by an unemployed individual, the higher is their attitude towards considering a multichannel approach. 
Table 1 shows that unemployed individuals with and without previous job experience search for a job using, on average, three macro-channels. This value has remained somewhat stable over recent years (that is, from the inclusion of the internet as a job search channel in the LFS; see Fig. 3 in "Appendix 2"). Figure 2 illustrates the composition of the multichannel attitude in a graphical way. Firstly, we do not observe important differences between unemployed individuals with and without previous job experience. Secondly, we note that unemployed individuals who search for a job using one channel (a small proportion of the sample) mainly choose to use the informal network.

As an overall view on the chosen job search channels, Table 1 reports that more than $80 \%$ of the unemployed considered the informal network, followed by public competitions or direct contact (more than 70\%), and the internet (about 60\%). From a long-term historical perspective (Fig. 4 in "Appendix 2"), we note a rapid growth of the use of the internet for job searches, in line with the entrance of information technology in many domains of life, while newspaper advertisements and employment agencies are losing attractiveness. This last finding might reflect a lower quality of the services or fewer (expected) successful opportunities in finding a job through these channels (e.g. Bachmann and Baumgarten 2013).

\subsection{Observed Characteristics of Unemployed Individuals}

In Table 1, we report descriptive statistics of the main observable characteristics (available from the survey) of the samples of unemployed individuals with and without previous job experience, respectively. Such characteristics include socio-demographic information (e.g. age, education, marital status); the characteristics of the individual's previous job (for unemployed individuals with experience; e.g. sector of employment, the typology of occupation); the duration of the job search; and the macro-area of residence in Italy.

We note that the sample of unemployed individuals without previous job experience is mainly composed of young people who are likely to be experiencing the school-to-work transition process. Albeit with a marginal frequency, we note the presence of unemployed individuals who decide to enter the labour market for the first time at a later age. The descriptive analysis highlights as a crucial issue the fact that entering the labour market for the first time can be a very challenging task (about 63\% state that they searched for a job for more than 12 months), especially in the regions of southern Italy and of the major islands (62\% of the sample).

The sample of unemployed individuals with previous job experience includes mainly people aged over 34 years old and with a low educational level (56\% of the sample has not achieved a secondary educational level). Empirical studies in Italy have shown that more highly educated people have a higher probability of exiting the state of unemployment (e.g. Zanin and Calabrese 2017). In light of this, unemployed individuals with a low level of education are likely to be characterised by a long-term period of unemployment. Unemployed individuals with experience have previously worked in the service sector (56\% of the sample) and were mainly employees (88\%), and only a marginal share were self-employed (7\%) or employed with a collaboration agreement (5\%). 


\section{Methods}

As a limitation of the descriptive analysis, we are not able to isolate the effects of specific characteristics of the two sub-groups in an effective way. This aim can be achieved using modelling techniques. We begin our analysis by exploring the determinants of the number of job-search channels (as a proxy for multichannel attitude) by distinguishing between unemployed individuals with and without previous job experience using the Poisson regression model (Sect. 4.1). Secondly, we examine the determinants of the choice of each channel by accounting for observable variables and unobservables using a multivariate probit model (Sect. 4.2).

\subsection{Determinants of the Number of Job-Search Channels: A Poisson regression}

Let $1 \leq y_{i t} \leq 5$ be the number of job search channels (a proxy of the multichannel attitude) considered by the ith unemployed individual at time $t$. This is a limited dependent variable that takes only positive integer values. Using a linear regression to model the response-covariates relationship, we would fail to consider the limited number of possible values of the outcome variable. The Poisson regression is the most appropriate method to overcome the limits of linear regression (Tutz 2012). This is because the error process is assumed to follow a Poisson distribution.

The general model structure to study the response-covariates relationship is as follows:

$$
\mathbf{y}=\mathbf{g}^{-1}(\boldsymbol{\eta})+\boldsymbol{\epsilon}, \quad \mathbf{y} \sim F,
$$

where $\mathbf{g}^{-1}(\boldsymbol{\eta})=\boldsymbol{\mu}=\mathbb{E}(\mathbf{y} \mid \mathbf{X}) \cdot \mathbf{g}(\cdot)$ denotes the known link function, and $\mathbf{X}$ is a matrix of observable explanatory variables, while $\boldsymbol{\epsilon}$ is the error term defined as $\boldsymbol{\epsilon} \equiv \mathbf{y}-\mathbf{g}^{-1}(\boldsymbol{\eta})$ with $\mathbb{E}(\boldsymbol{\epsilon} \mid \mathbf{X})=\mathbf{0}$, and $F$ is an exponential family distribution.

The probability density function is

$$
\operatorname{Pr}(Y=y)=\left(\frac{e^{-\mu} \mu^{y}}{y !}\right)
$$

while the log-likelihood is given by

$$
\ln L=\sum_{j=1}^{n}\left\{-e^{\xi_{j}}+\xi_{j} y_{j}-\ln \left(y_{j} !\right)\right\}
$$

where $\mu$ is the average number of events, $\xi_{j}=\boldsymbol{x}_{j} \boldsymbol{\beta}, e$ is the base of the natural logarithms ( $(n)$ and $y$ ! is the factorial of $y$. The model can be estimated using (pseudo-)maximum likelihood (ML). This method allows us to compute robust standard errors when the model is well specified, but the error distribution is not a Poisson distribution (e.g. Santos Silva and Tenreyro 2010, 2011). The marginal effects are computed as the partial derivative, $\partial y_{i} / \partial x$, while the relative confidence intervals are obtained using the delta method.

To explore the determinants of the number of job search channels for unemployed individuals with previous job experience, we re-write (1) as follows: 


$$
\begin{aligned}
& y \sim \underbrace{\operatorname{Poisson}(\boldsymbol{\mu}),}_{\boldsymbol{\mu}} \\
& y=\underbrace{\operatorname{ex},}_{\text {exp }\left\{\mathbf{X}_{\text {SED }} \boldsymbol{\beta}_{\text {SED }}+\mathbf{X}_{\text {LastJob }} \boldsymbol{\gamma}_{\text {LastJob }}+\mathbf{X}_{\text {Spatial }} \boldsymbol{\omega}_{\text {Spatial }}\right\}},
\end{aligned}
$$

where the chosen link function $\mathbf{g}$ is $\ln . \mathbf{X}_{S E D}$ includes variables of a socio-economic, demographic nature, $\mathbf{X}_{\text {LastJob }}$ refers to variables related one's previous job, $\mathbf{X}_{\text {Spatial }}$ refers to spatial information (see Sect. 3 for details), while $\boldsymbol{\beta}_{S E D}, \boldsymbol{\gamma}_{\text {LastJob }}$, and $\boldsymbol{\omega}_{\text {Spatial }}$ are the parameters to be estimated. The model for unemployed individuals without previous job experience is estimated by excluding $\mathbf{X}_{\text {LastJob }}$ from (4).

\subsection{Determinants of Multichannel Job-Search Behaviour: A Multivariate Probit Model}

We consider $K$ possible job search channels. According to the definition of unemployment (see footnote 1), people must have activated at least one job search channel in the period of observation. Thus, we observe $2^{K}-1$ combinations of the $K$ different channels. Let $C_{k}^{*}$ be the latent variable associated with the k-th job-search channel, where $k=1, \ldots, 5$, as described in Sect. 3.1. We explore the determinants of the of multichannel job-search behaviour using a multivariate probit model. The model is specified as follows:

$$
C_{i k}^{*}=X_{i k} \Psi_{i k}+\epsilon_{i k}, \quad \text { where } k=1, \ldots, 5
$$

where $C_{i k}=1$ if $C_{i k}^{*}>0$, and 0 otherwise. For notational convenience, we suppress the subscript $i$ that identifies the $\mathrm{i}-t h$ unit in the sample, $i=1, \ldots, n$. $\boldsymbol{X}_{k}=\left(X_{i k ; S E D}, X_{i k ; \text { LastJob }}, X_{i k ; \text { Spatial }}\right)$, while $\boldsymbol{\Psi}_{k}=\left(\boldsymbol{\beta}_{\text {SED }}, \boldsymbol{\gamma}_{\text {LastJob }}, \boldsymbol{\omega}_{\text {Spatial }}\right)$ includes the parameters to be estimated. The model for unemployed individuals without previous job experience is estimated by excluding $\mathbf{X}_{\text {LastJob }}$ from (5). $\epsilon_{i k}$ are error terms distributed as multivariate normal, each with a mean of zero and a symmetric variance-covariance matrix $\mathbf{\Sigma}$ defined in our case as

$$
\boldsymbol{\Sigma}=\left[\begin{array}{cccc}
1 & \rho_{12} & \ldots & \rho_{15} \\
\rho_{21} & 1 & \ldots & \rho_{25} \\
\vdots & \vdots & \ddots & \vdots \\
\rho_{51} & \rho_{52} & \ldots & 1
\end{array}\right]
$$

The correlation coefficient $(\rho)$ between the stochastic components captures the impact of unobservable confounders (that is, unobservable common factors between utility functions that are hardly measurable and not measured in the survey used). We have assumed that such unobservables may be represented by aspects of the personality sphere, such as motivation, self-control, and preference, and be integral parts of the decisional process of a multichannel job search. Some studies focusing on the role of aspects of personality in the labour market find that (work) motivation is a predictor of job-search behaviour (e.g., Zikic and Saks 2009; Tso et al. 2010), which, in turn, may amplify, compensate, or have no effect on self-control (that is, the ability to control one's thoughts and actions in a job search; see Baay et al. 2014 and references therein). Preference or time preference is another factor affecting job-search behaviour. The process of searching for a job is an unpleasant and costly activity whose benefits materialise only in a future that is uncertain in its duration (e.g. Della Vigna and Paserman 2005; Constant et al. 2011). In this regard, some studies support the model of hyperbolic time preferences, in which job seekers are sensitive to job 
search costs and are little willing to invest in search efforts (e.g. Della Vigna and Paserman 2005). The statistical significance, sign, and magnitude of the estimated correlation coefficients suggest the direction of the correlation and the importance of such factors as a whole in the process of a multichannel job search.

The log-likelihood function of the multivariate probit model is given by

$$
L=\sum_{i=1}^{n} \log \operatorname{Pr}\left(\boldsymbol{C}_{\boldsymbol{i}} \mid \boldsymbol{\mu}_{\boldsymbol{i}}, \mathbf{\Omega}\right)
$$

where $C_{i}=\left(C_{1}, C_{2}, \ldots, C_{5}\right) \quad$ and $\quad \mu_{i}=\left(S_{i 1} \Psi_{i 1}^{\prime} X_{i 1}, S_{i 2} \Psi_{i 2}^{\prime} X_{i 2}, \ldots, S_{i 5} \Psi_{i 5}^{\prime} X_{i 5}\right) \quad$ with $S_{i k}=2 C_{i k}-1$. The matrix $\Omega$ include the elements

$$
\begin{aligned}
& \Omega_{k k}=1 \text { for } k=1, \ldots, 5 \\
& \Omega_{21}=\Omega_{12}=S_{i 2} S_{i 1} \rho_{21}, \\
& \Omega_{31}=\Omega_{13}=S_{i 3} S_{i 1} \rho_{31}, \\
& \Omega_{41}=\Omega_{14}=S_{i 4} S_{i 1} \rho_{41}, \\
& \Omega_{51}=\Omega_{15}=S_{i 5} S_{i 1} \rho_{51}, \\
& \Omega_{32}=\Omega_{23}=S_{i 3} S_{i 2} \rho_{32}, \\
& \Omega_{42}=\Omega_{24}=S_{i 4} S_{i 2} \rho_{42}, \\
& \Omega_{52}=\Omega_{25}=S_{i 5} S_{i 2} \rho_{52}, \\
& \Omega_{43}=\Omega_{34}=S_{i 4} S_{i 3} \rho_{43}, \\
& \Omega_{53}=\Omega_{54}=S_{i 5} S_{i 3} \rho_{53}, \\
& \Omega_{54}=\Omega_{45}=S_{i 5} S_{i 4} \rho_{54} .
\end{aligned}
$$

A multivariate normal distribution function can be expressed as the product of sequentially conditioned univariate normal distribution functions. The most commonly used method for evaluating the multivariate normal distribution function is the Geweke-Hajivassiliou-Keane (GHK) smooth recursive conditioning simulator implemented in the Stata program mvprobit (Cappellari and Jenkins 2003). We also apply a likelihood ratio test of a multivariate probit model against $\mathrm{K}$ independent univariate probits. The rejection of the null hypothesis $\left(H_{0}=\rho_{21}=\rho_{31}=\cdots=\rho_{54}=0\right)$ using a $\chi^{2}$ test (e.g. Kiefer 1982) suggests the importance of using a multivariate probit model rather than univariate probit models to explore the determinants of the use of different job-search channels. The average marginal effects (AMEs) of each explanatory variable and the associated $95 \%$ confidence intervals (CIs) are computed using 10,000 coefficient vectors simulated from the posterior distribution of the estimated parameters.

\section{Results}

We describe the main evidence emerging from the analysis of the determinants of jobsearch channels used by unemployed individuals with and without previous job experience. In Sect. 5.1, we provide insight on the determinants that most affect the number of channels used for job searches, while in Sect. 5.2, we comment on the observable factors and the pairwise correlation coefficients across the residuals of the model that characterise the choice of the typologies of channels. As a robustness analysis, we estimate the models for each macro-area of the country. We only comment on relevant findings emerging from this 


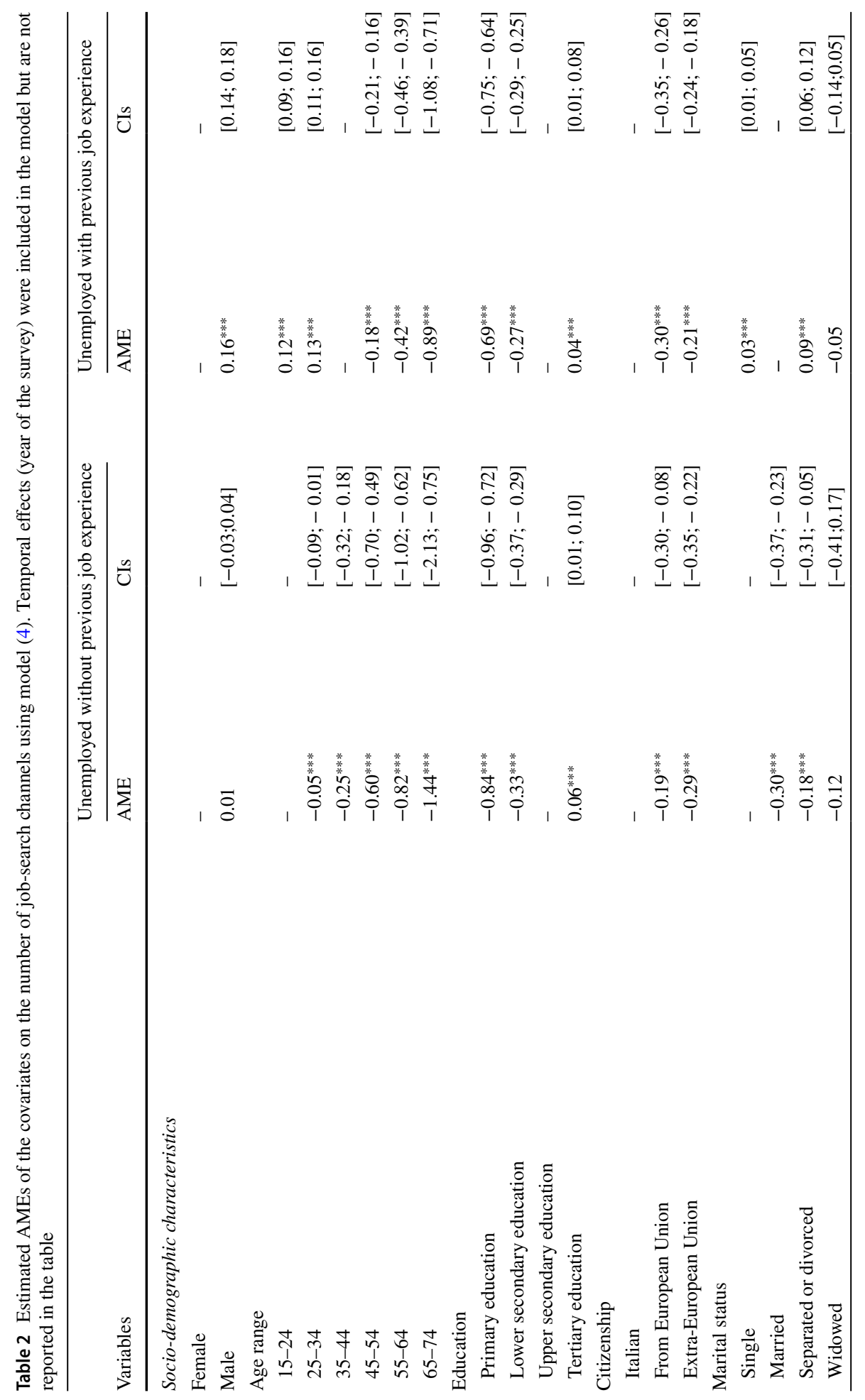




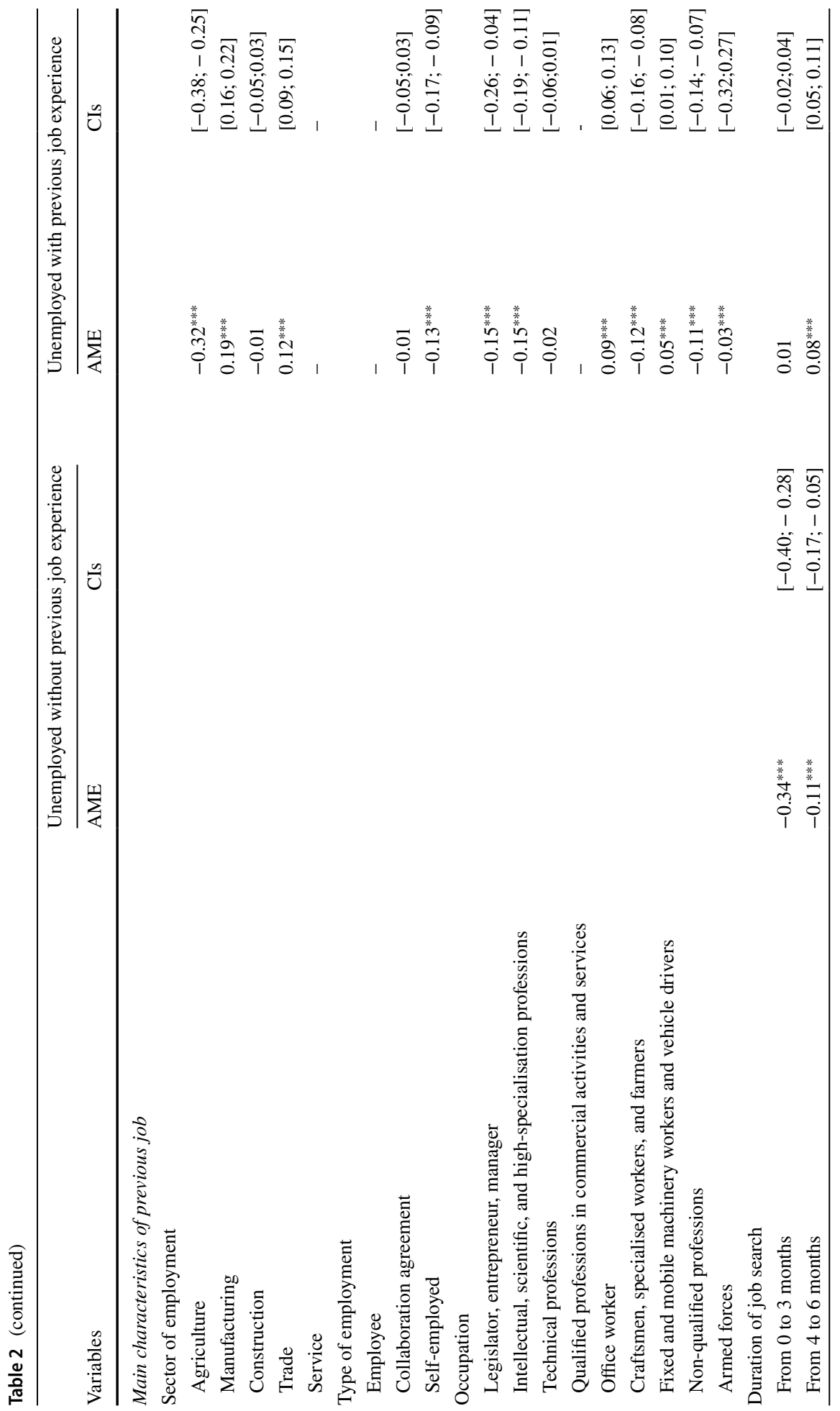




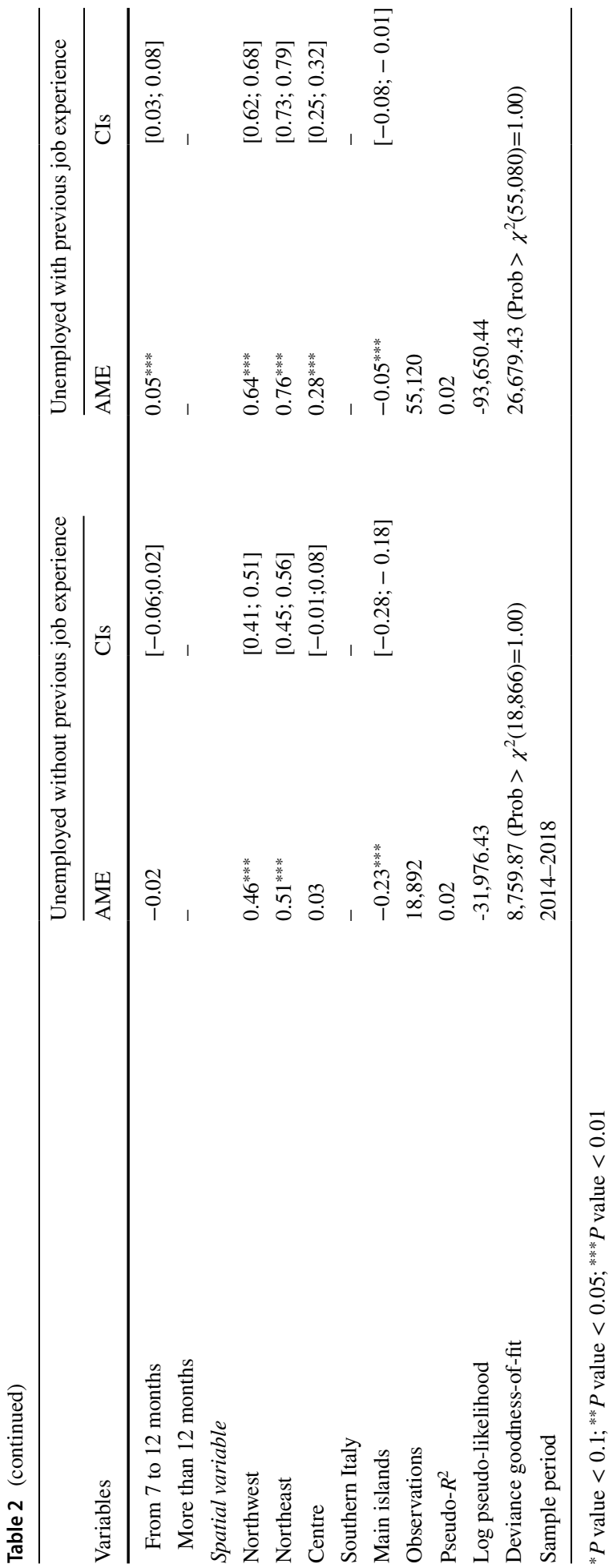


analysis in Sects. 5.1 and 5.2 (in terms of AMEs and the associated CIs), while the full tables with the estimated AMEs and the associated CIs are available upon request.

\subsection{Determinants of the Number of Job-Search Channels}

To explore the factors affecting the number of job-search channels used (in other words, the multichannel attitude as a whole), we estimate a Poisson regression by distinguishing between the samples of unemployed individuals with and without previous job experience, respectively. Table 2 reports the AMEs and the associated 95\% CIs of each observable factor considered in the analysis.

For the socio-demographic characteristics, we choose a different reference category for age and marital status when estimating model (4) for the unemployed individuals with and without previous job experience. This choice is motivated by the different structure of the samples, as reported in Table 1.

Gender is not a significant determinant of the number of job-search channels for unemployed individuals entering the labour market for the first time (see also Caliendo et al. 2011). By estimating the model separately by macro-area of residence, we do not find gender differences within northern Italy (both in the Northwest and Northeast), while a higher multichannel attitude for males compared to females is observed for southern Italy (AME equal to 0.06 with CIs $0.00 ; 0.11$ ) and the main islands (AME equal to 0.14 with CIs $0.06 ; 0.21$ ). This is in line with the literature showing the presence of important disadvantages for (young) unemployed women in these areas of the country (see also Baussola et al. 2015), also reflected in multichannel search behaviour. For the sample of unemployed individuals with previous job experience, we note that males show a higher multichannel job search attitude with respect to females, and this finding is confirmed in all of the geographical macro-areas of Italy (see also De Paola et al. 2015).

According to Bachmann and Baumgarten (2013), the number of job-search channels tends to decrease with age, especially for unemployed individuals who aim to enter the labour market for the first time. Looking at the difference between unemployed individuals with and without previous job experience, we note that for the latter group, middle-aged individuals (45-54 years old) tend to consider almost one channel fewer (AME equal to - 0.60) than younger ones (reference category). Instead, as compared to the reference category (35-44 years old), when unemployed individuals have job experience, the decrease in multichannel attitude becomes more important only after 65 years of age (AME equal to - 0.89). The difficulty in employment re-entry of unemployed individuals close to retirement, as observed in the study by Zanin and Calabrese (2017), is thereby the result of a mix of issues that, in a vicious loop, go from the lack of some individual skills (e.g., motivation, willingness to lifelong learning, technology skills) and less willingness to move for a job to matters of business management (e.g., firms have higher costs when hiring an older unemployed person than a younger one), and so on, leading to the discouragement of unemployed individuals. Due to the aforementioned or other barriers, we assume this might lead the oldest unemployed individuals to search for a job with less effort.

Job-seekers who achieved tertiary education have a higher multichannel attitude in the job-search process than lowly educated unemployed individuals. This evidence is in line with expectations and the existing literature (e.g. Bachmann and Baumgarten 2013; Weber and Mahringer 2008). In particular, we find an accentuated positive effect of a better education on multichannel attitudes among the unemployed without job experience who reside in southern Italy (AME equal to 0.16 with CIs $0.09 ; 0.24$; not significant 
for the rest of the country). For those who have previous job experience, the positive effect is found for the centre and southern areas of Italy (AMEs equal to 0.08 (with CIs $0.01 ; 0.14$ ) and 0.14 (with CIs $0.07 ; 0.21$ ), respectively). This evidence may suggest how a higher education can "protect" the unemployed who reside in the southern areas of the country (which are characterised by higher unemployment rates than northern areas) from discouragement behaviour in their job search attitude.

Unemployed individuals who are married and lack job experience use a lower number of search channels to find a job than single individuals (AME equal to - 0.30). In contrast, if the unemployed individuals have previous job experience and are divorced or single, they have a higher multichannel attitude than married unemployed individuals (AME equal to 0.09). In this regard, the presence/absence of labour income from other household members and the financial need in the household can play a crucial role in affecting job-search behaviour. Given the absence of financial variables in the LFS, we are not able to control for factors of household economic well-being and possible economic shocks deriving from the unemployment of one or more members in the household.

The prolonged duration of the search for an individual's first or new job is a crucial issue not only for unemployed people (see Fig. 1) but also for policymakers. This is because long-term unemployment has direct negative effects not only on the unemployed individuals (e.g., on health) but also on their families and society overall (e.g., Bejaković and Mrnjavac 2018). Among possible motivations are the discouragement effect and intrinsic work motivation. In light of this, reverse causation between duration of the job search and multichannel attitude is plausible. Here, we do not focus on this matter as it goes beyond the scope of this study. In separately analysing unemployed individuals with and without previous job experience, our findings suggest that the latter tend to search in a less multichannel manner (especially in the first three months of their job search) than those who have been unemployed for a long time. In contrast, unemployed individuals with previous job experience search for a new job by showing a peak in their multichannel attitude from the fourth to the sixth month (AME equal to 0.08), followed by a decrease from the seventh to the twelfth month (AME equal to 0.05) which is likely attributable to the aforementioned motivations.

For the job-experienced unemployed individual, the characteristics of their recent history in the labour market contribute to the heterogeneity of their choice of job-search channels. Unemployed individuals who worked in the agricultural sector tend to search for a new job by considering fewer channels than workers with experience in firms or institutions in the service sector (reference category). This evidence might be motivated by the seasonality of most jobs in the agricultural sector (see also Bachmann and Baumgarten 2013), which is particularly developed in the southern areas for the characteristics of the Italian economy (see also Taylor and Bradley 1997). We find support in this regard from the estimation of the model by macro-area of residence. Specifically, we estimate that the effect of having worked in the agricultural sector is significant and has a negative sign (as compared to the reference category) only in the centre and south of Italy (AMEs equal to -0.19 (with CIs $-0.30 ;-0.05$ ) and -0.50 (with CIs $-0.62 ;-0.37$ ), respectively). In contrast, unemployed individuals from the manufacturing (AME equal to 0.19) and trade (AME equal to 0.12) sectors take more channels into consideration for their job search than unemployed individuals who lost their job in the service sector. The multichannel job search attitude of unemployed persons who were employed in firms through a collaboration agreement does not differ significantly from that of an employee. However, we found some differences by macro-area, with a positive and significant impact on multichannel job 
search attitude in southern Italy (AME equal to 0.10 with CIs $0.01 ; 0.19$ ) and an opposite impact in the major Islands (AME equal to -0.05 with CIs $-0.09 ;-0.01$ ).

Unemployed individuals who were in executive professions or fixed and mobile machinery workers and vehicle drivers have a higher multichannel attitude than qualified professions in commercial activities and services (the reference category). In contrast, highly skilled professionals (such as legislators, entrepreneurs, managers, intellectuals, scientific and high-specialisation professions) show lower diversification in job searches than the reference category. This is because they most likely focus their interest on those channels that they believe can return better chances of finding a job coherent with their skills.

Another factor of interest is the spatial difference in the number of channels used for job searches. Specifically, we found the highest multichannel attitude in the richest area of the country (northern Italy), where the transition from the status of unemployed to employed is more likely (Zanin and Calabrese 2017). Further details and evidence of jobsearch patterns can emerge from a more specific analysis of job-search methods (see the next section).

\subsection{Determinants of the Typology of Job Search Channels}

As mentioned in Sect. 4.2, we estimate a multivariate probit model for unemployed individuals either with or without previous job experience using the method of simulated maximum likelihood (SML), also known as a GHK simulator (see also Greene 2012, p. 667). The SML estimator is consistent when the sample size and the number of draws tend towards infinity. Cappellari and Jenkins (2003) showed that when the number of the draw, $D$, is greater than $\sqrt{N}$, then the parameter estimates are robust for different initial seed values. We apply this rule in our model estimation process.

Tables 3 and 5 report the AMEs of the observable factors included in (5) for the sample of unemployed individuals both with and without previous job experience, respectively. Specifically, we include socio-demographic characteristics, duration of the job search up to the time of the survey, spatial variables, and some characteristics of their previous job for unemployed individuals who have prior job experience.

In accordance with the estimated models of job-search intensity, we have chosen a different reference category for age and marital status when estimating model (5) for the unemployed individuals with and without previous job experience.

Among demographic variables, we note that unemployed males with previous job experience are more likely than females to search for a job across the different search channels, and especially using direct contact (AME equal to 0.07; see also Ponzo and Scoppa (2010) and Bachmann and Baumgarten (2013) for further evidence in this regard). The higher multichannel job search attitude of males is in line with evidence from Sect. 5.1. The estimation of model (5) adds knowledge about how this effect is distributed across the search channels. Gender is, instead, not a statistically significant variable for unemployed individuals without job experience, with the exception of the channel of direct contact with firms. For the latter group of unemployed individuals, some spatially heterogeneous evidence is detected from the model estimated separately by geographical area of residence. For instance, we find that males in southern Italy have a higher probability of using the agency channel than females (AME equal to 0.03 with CIs 0.01;0.05), while for those located in the main islands of Italy, this difference appears for direct contact with firms (AME equal to 0.07 with CIs $0.04 ; 0.11$ ). 


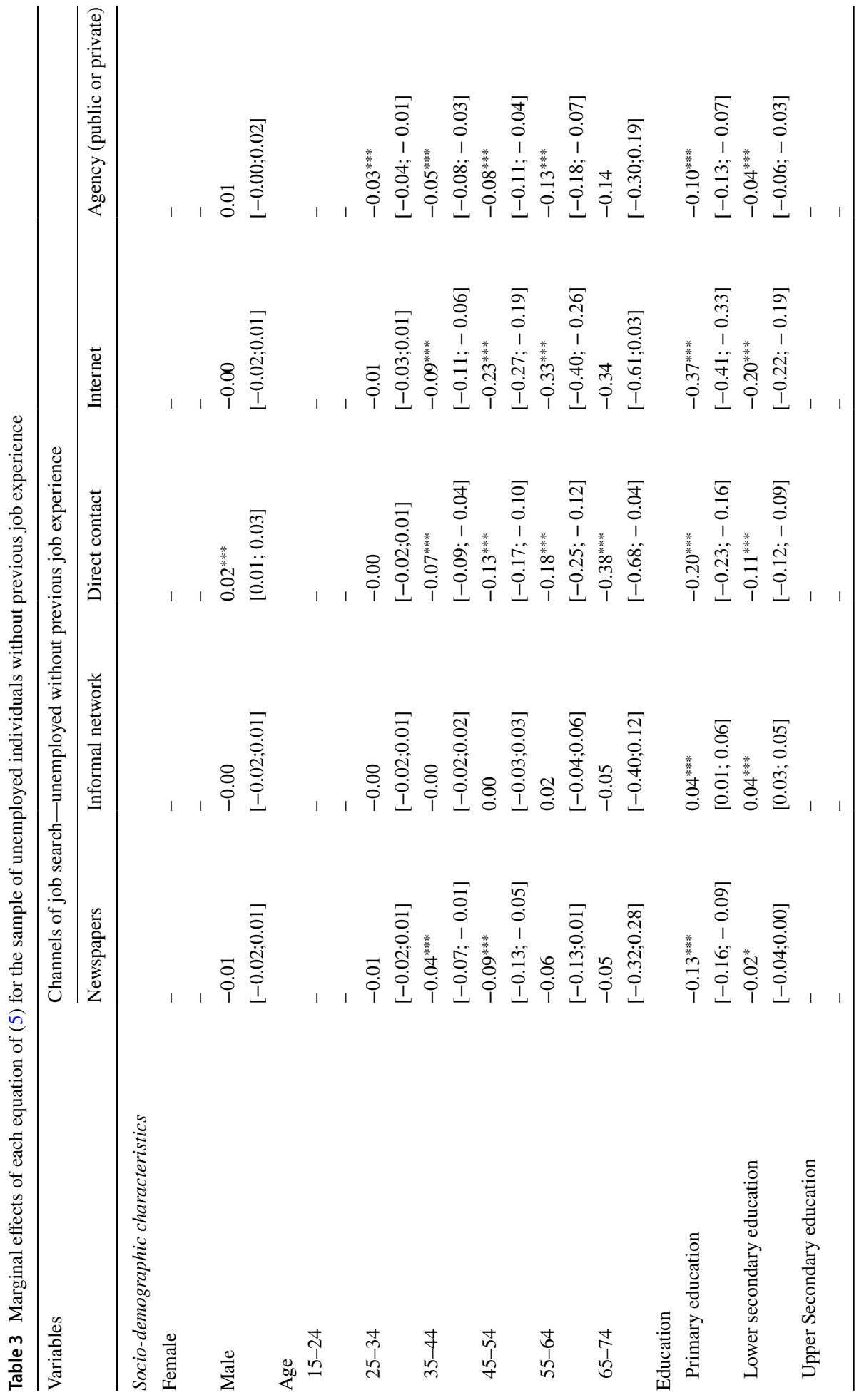




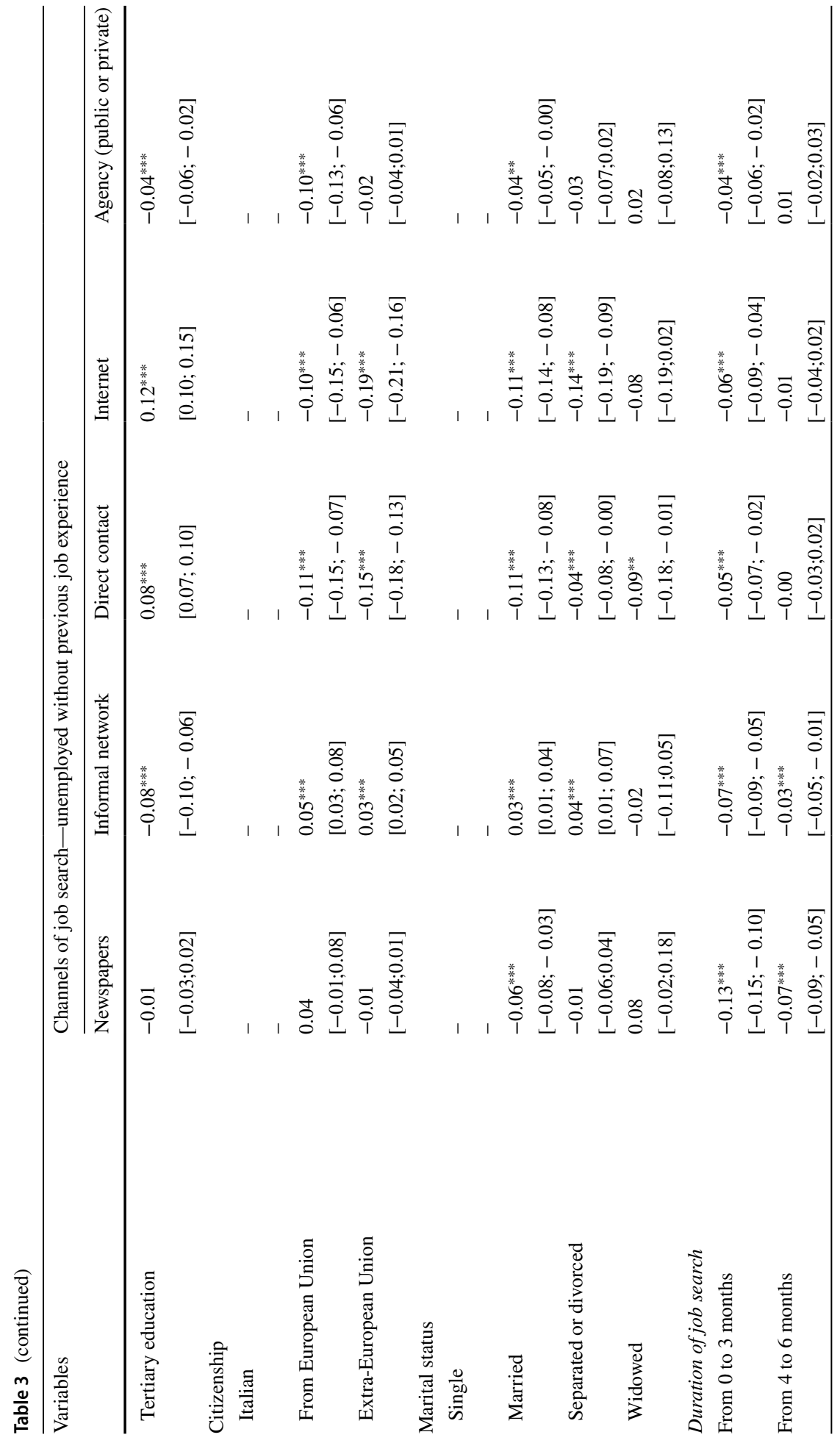




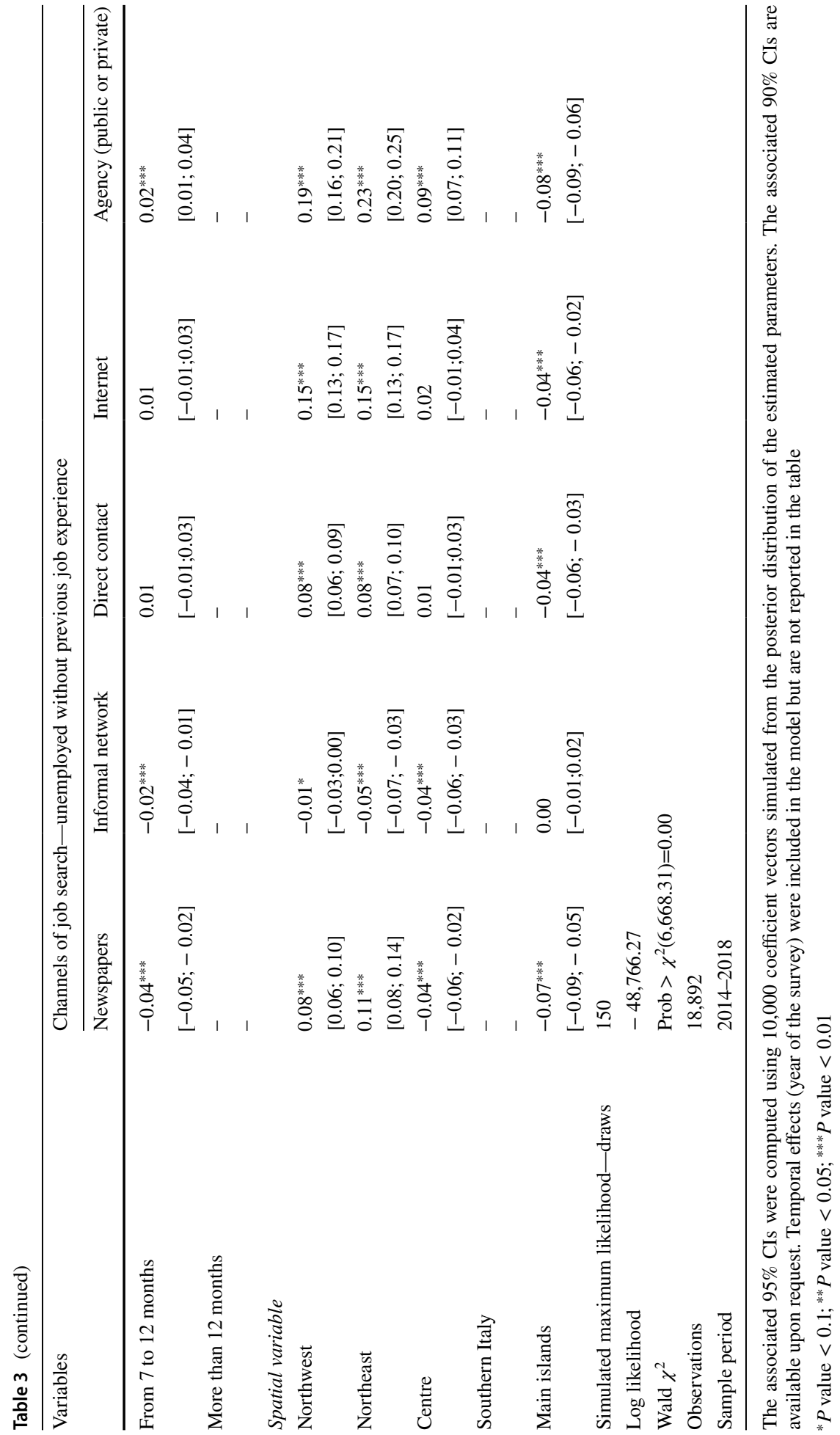


The age of the unemployed individuals highlights changes in job-search behaviours between generations. As expected, we found that older unemployed individuals with previous job experience (55-74 years; the generation of baby boomers) are less likely than younger individuals (younger than 34 years) to use the channels of direct contact and the internet (AME equal to -0.26 and -0.38 , respectively). This evidence is explained by the fact that younger people born in the era of digital development are more likely than older ones to use job-search channels on the internet, using the nowcommon devices such as PCs, tablets, and smartphones. Of interest, we note that there are no significant differences in the choice of informal network use across ages. This suggests that the informal network represents a channel chosen by both unemployed groups (with previous job experience or not). This evidence is also consistent when estimating the models by macro-area.

The educational level reached is a proxy of human capital, which includes a set of heterogeneous, intangible skills acquired during one's educational path. Compared to the reference category (upper secondary education) better-educated unemployed individuals, both with and without previous work experience, prefer the internet (AME equal to 0.11 and 0.12 , respectively, for the unemployed with and without professional experience) and direct contact with firms (AME equal to 0.07 and 0.08 for the unemployed with and without professional experience, respectively) instead of informal network channels (AME equal to -0.06 and -0.08 for the unemployed with and without professional experience, respectively). This is in line with the existing literature (see, for example, Mariani et al. 2020). The internet offers a wider choice of job advertisements than traditional channels (e.g. local newspapers and agencies) and the possibility of extending the search outside the city or region of residence (see also Mang 2012). This last point is especially important for the unemployed who live in regions of southern Italy, where official statistics record higher structural unemployment rates than the rest of the country, and thus where the unemployed could encounter the greatest difficulties in or barriers to finding a job consistent with their training and/or skills derived from previous work experience. By running the model (5) by macro-area, we find that better-educated unemployed people who reside in the southern regions of Italy are more likely than those who have obtained a secondary education to consider the internet as a channel for searching for work (AMEs equal to 0.16 (with CI: $0.12 ; 0.20$ ) and 0.20 (with EC: $0.16 ; 0.24$ ) for the unemployed with and without previous work experience, respectively). However, as a possible limit, the internet remains a formal channel that does not reduce the potential problem of information asymmetry between candidates and recruiters, as can happen when considering the informal network. The poorly educated unemployed, on the other hand, seem to rely more on informal networks than on the internet or direct contact with entrepreneurs (for example, see Ponzo and Scoppa 2010). As noted by Fouarge et al. (2013), less-educated workers are less willing to participate in (continuous) training, and this can affect the assessment of their skills when looking for a job using other channels (problem of skills mismatch). Therefore, the informal network can be considered a viable alternative.

In contrast to Bachmann and Baumgarten (2013), we found that the duration of the job search has a significant impact on the choice of job-search channels. The difference in results might, however, be attributable to our focus on a single country rather than a panel of European countries. We found that individuals who aim to enter the labour market for the first time show a lower probability of searching through job advertisements in newspapers or informal networks than the reference category (more than 12 months), especially in the first three months of searching. In the early period of unemployment, we note that individuals with previous job experience have a lower probability than the reference category 
of choosing newspapers (AME equal to - 0.07) and informal networks (AME equal to -0.03 ) as job search channels.

As regards the region of residence, we note that the use of the internet, agencies (public or private), and direct contact with firms are more likely to be pursued by unemployed individuals with or without previous job experience who reside in northern Italy (the most economically rich macro-area in terms of gross domestic product per capita) than those in southern Italy (the reference category). Notably, the informal network channel is more likely be chosen by unemployed individuals who reside in the southern regions compared to those in the northern regions. Ponzo and Scoppa (2010) claim that the southern areas of the country are characterised by a mix of factors associated with high structural unemployment rates, low social capital, and strong social ties (see also Zanin 2013), which might favour the practice of searching for employment through family members or friends.

For unemployed people with previous work experience, some interesting insights emerge from their last job. The unemployed who were employed in the manufacturing sector show a higher probability of looking for a job using an agency (AME equal to 0.08), direct contact with companies, and the internet (AME equal to 0.06 for both channels) compared to those who were employed in the service sector. Some further differences emerge from the types of profession. Unemployed individuals who worked in medium-high qualified professions (e.g., executive professions, technical, intellectual, scientific, highly specialized professions, and office workers) have a higher probability of searching for a new job using the internet than the reference category (qualified professions in commercial activities and services). Moving on to the sector of employment, unemployed individuals who were employed in the manufacturing sector have a higher probability of searching for a new job through agencies, direct contact, and the internet (AMEs equal to 0.08, 0.06, and 0.06 , respectively) than the reference category (service sector). Similar evidence emerged for the unemployed who worked in the trade sector (AMEs equal to 0.06 for the internet, 0.04 for direct contact, and 0.03 for agencies). As regards those with experience in the construction sector, direct contact (AME equals to 0.03) and the informal network (AME equals to 0.02 ) have a higher probability of being used than the reference category. For the agricultural sector, the positive AME is only estimated for the informal network channel (AME equals to 0.01). These differences in the probability of choosing a specific(s) channel(s) might, in part, reflect the behaviour of entrepreneurs in selecting channels in which to post the job advertisements. In addition, the choice of the job-search channel(s) might also be attributable to the expected success of finding a job using a specific(s) channel(s) (see also Addison and Portugal 2002). Running model (5) for each macro-area, we find effects of the characteristics of previous job experience on outcomes mainly within the range of the estimated CIs for the whole country; this suggests the absence of substantial differences that merit being reported in the discussion.

Tables 4 and 6 show the estimated correlation coefficients, $\rho$, between each couple of job-search channels for the equations of unemployed individuals with and without experience, respectively. In "Appendix 3", we report the same information in Tables 8, 9, 10, 11, 12, 1314 and 15 but when model (5) is estimated for each macro-area of the country. From Tables 4 and 6, we do not observe important differences between unemployed individuals with and without previous job experience. The strongest correlation is between the channels of the internet and direct contact ( $\hat{\rho}$ equal to 0.40 and 0.37 for unemployed individuals without and with previous job experience, respectively). This suggests that unobservable factors (such as motivation, self-control, and preference, as described in Sect. 4.2) contribute to increasing the probability that unemployed individuals search for a job via the internet and through direct contact with firms. From a geographical 
$\therefore$

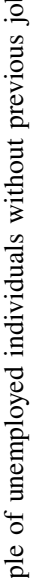

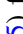

:

.

\section{(1)}




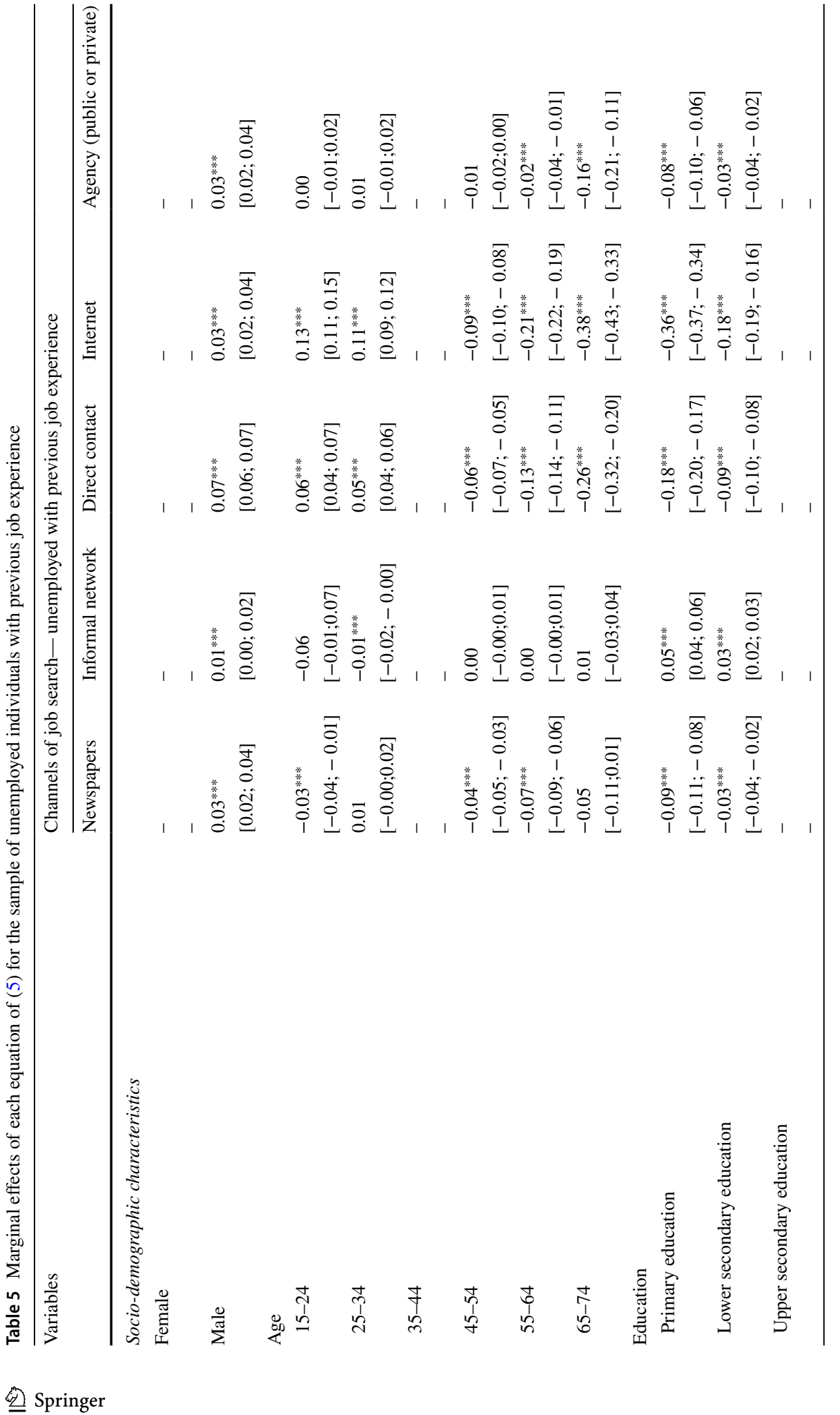




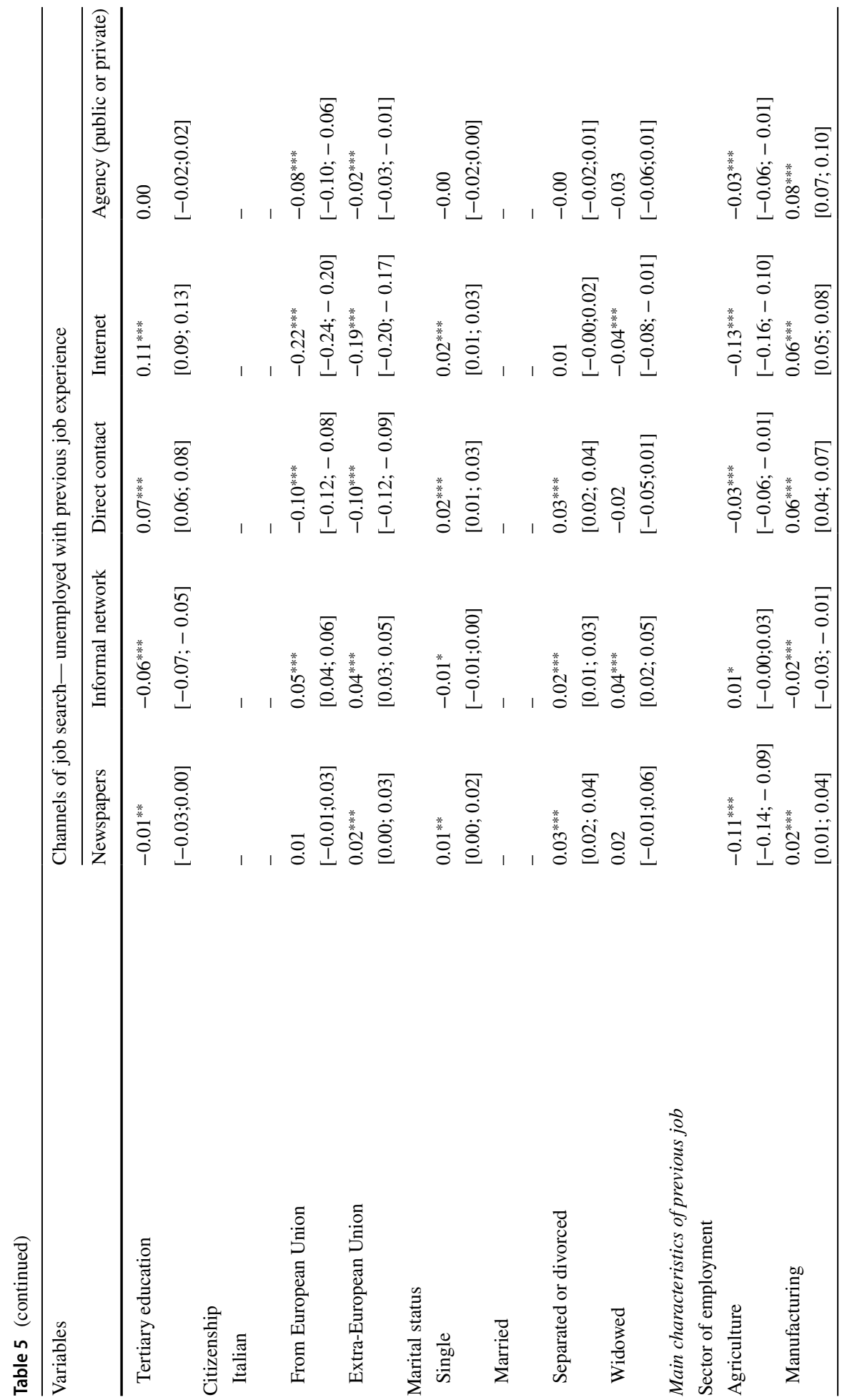




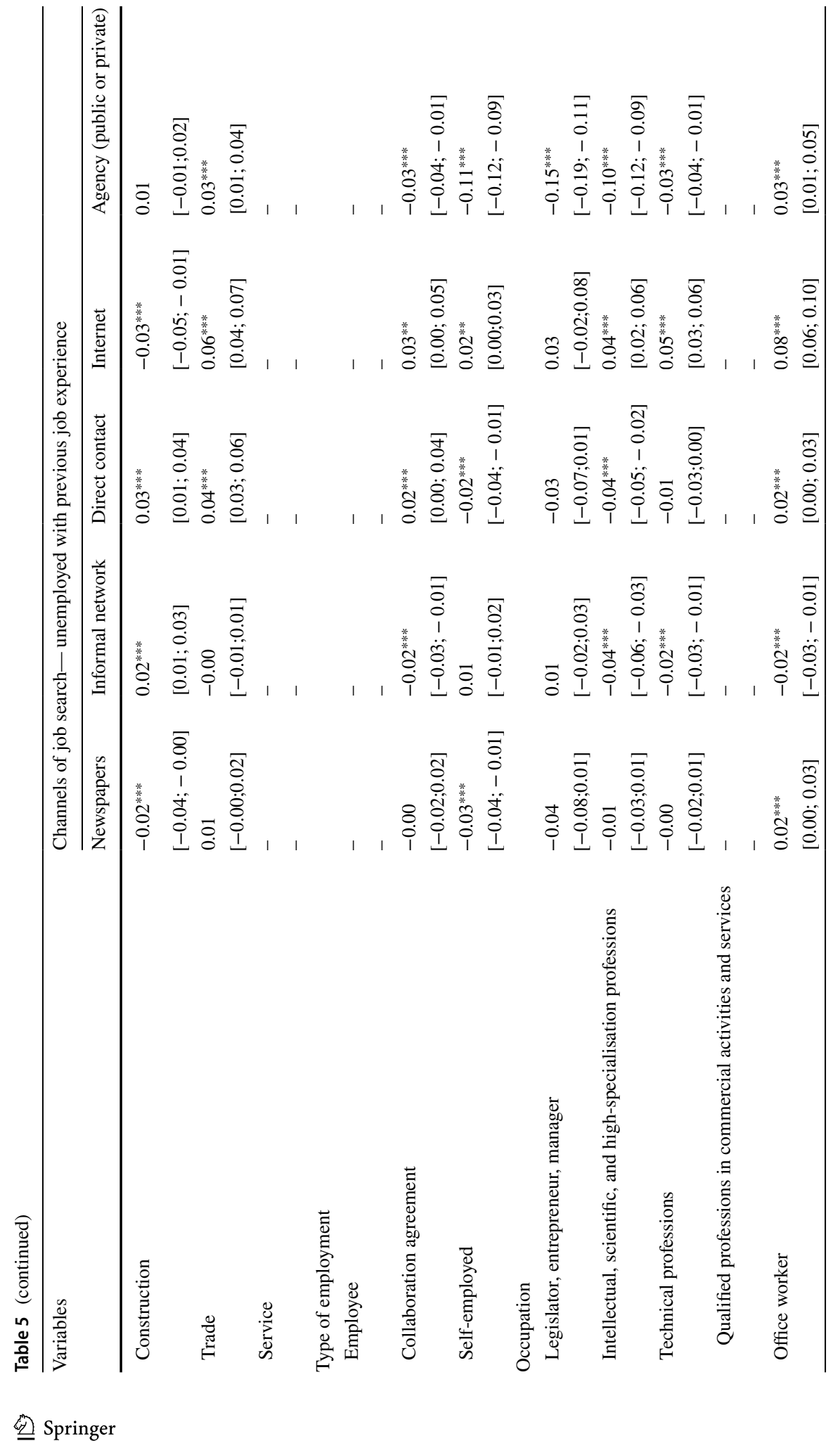




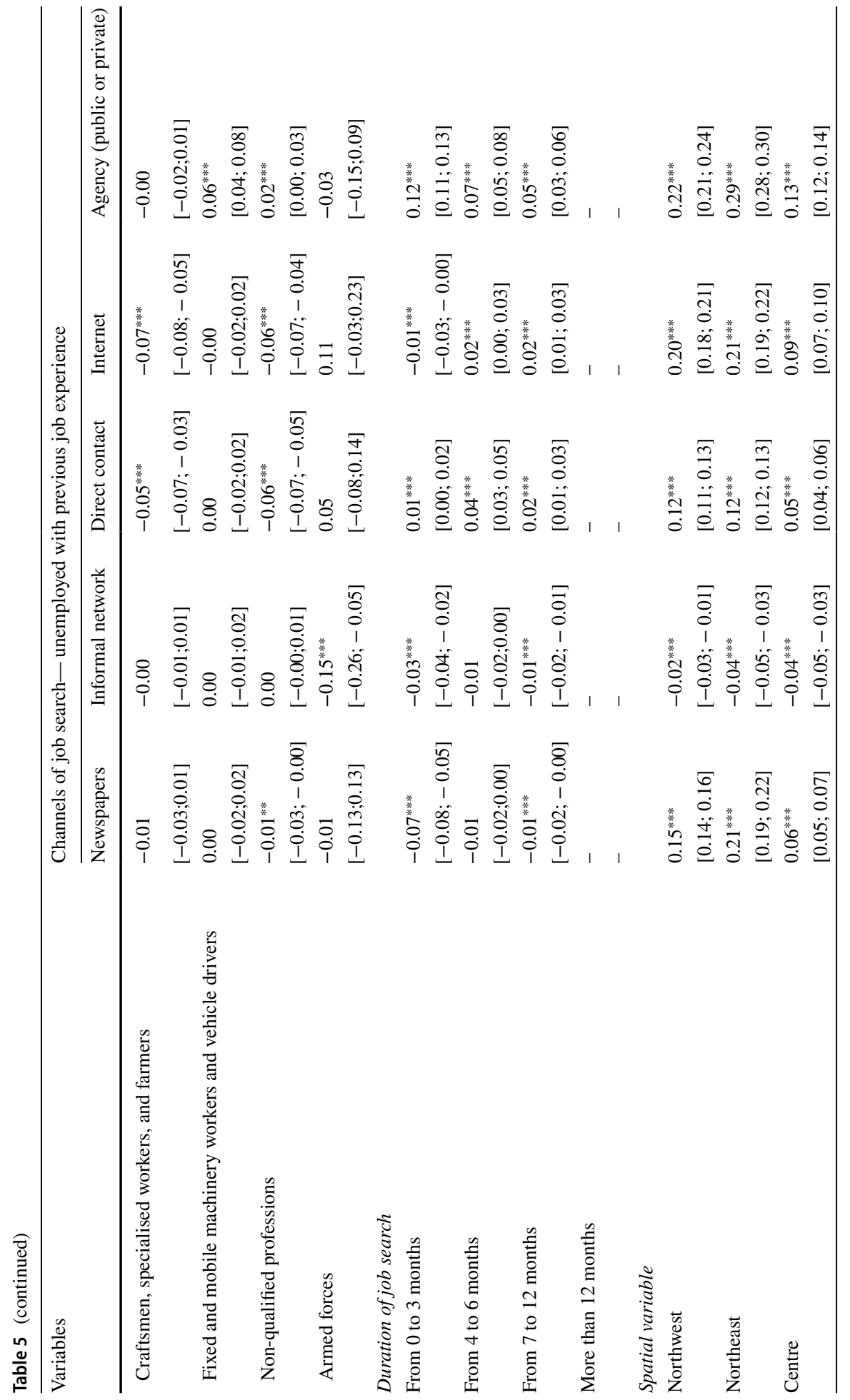




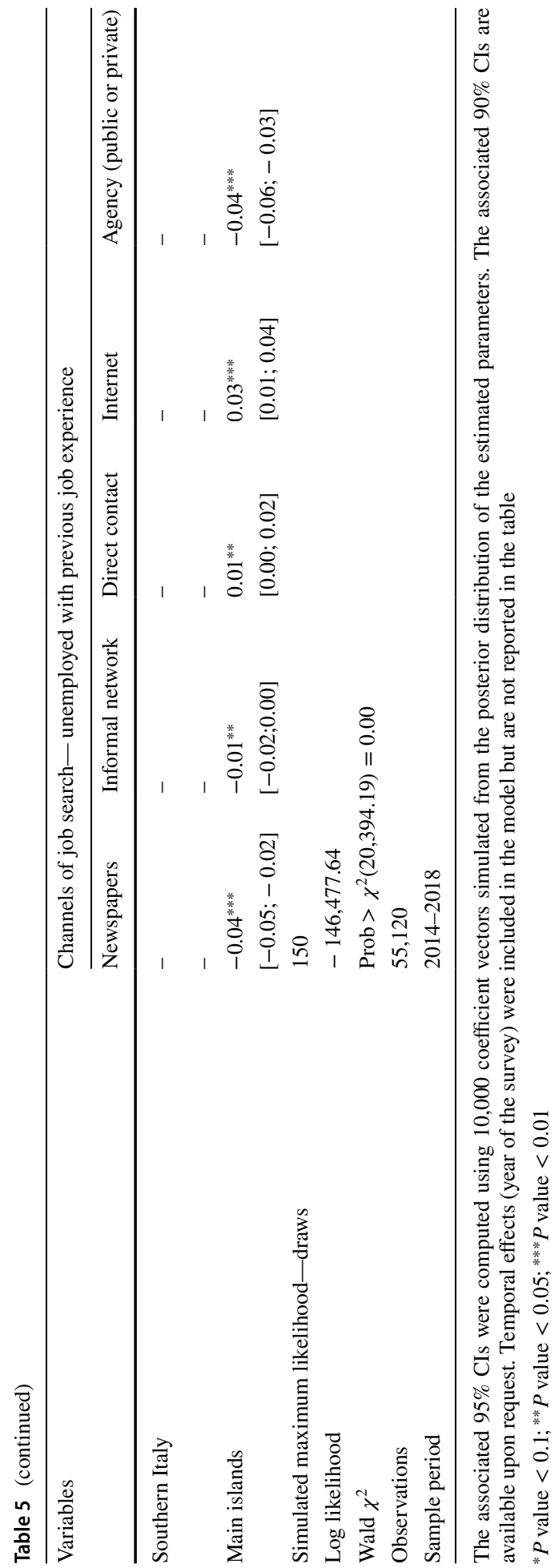




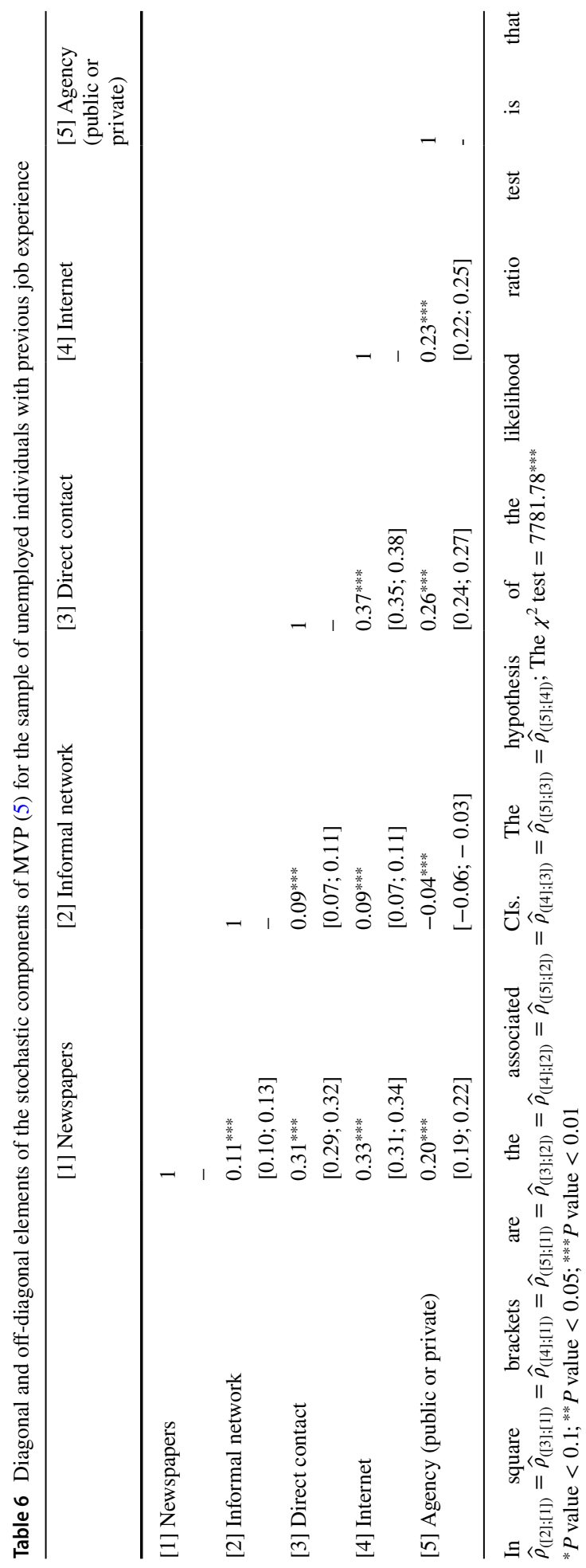


perspective, we find that these coefficients decrease in magnitude in the Northeast ( $\hat{\rho}$ equal to 0.30 for unemployed individuals without and with previous job experience, respectively) and in central Italy ( $\hat{\rho}$ equal to 0.32 and 0.29 for unemployed individuals without and with previous job experience, respectively). In contrast, from Tables 8, 9 and 15 in "Appendix 3", we note a strengthening of $\hat{\rho}$ in the northern areas of the country for informal networks and direct contact, with values around 0.25 , as compared to national values, estimated around 0.10 . This relationship becomes not significant when we look at the rest of the country. This does not mean that informal networks and direct contact with firms are not important in the rest of country, but only that there is not a significant association between these two channels in terms of unobservables (e.g., motivation, self-control, and preference) after accounting for a number of observables. This reading of unobservables provides insight into the multichannel job-search behaviour of unemployed individuals as compared to the estimation of a single equation for each search channel or to the exploration of multichannel attitudes in an aggregate way, as in Sect. 5.1. Specifically, the likelihood ratio test carried out for each estimated model (5) supports the importance of jointly estimating the equations representing each job-search channel considered in our analysis.

\section{Conclusions}

We explore the characteristics of unemployed individuals with and without previous job experience in terms of their use of different job-search channels (newspapers, agencies, informal networks, direct contact, the internet) in Italy. The unemployed with previous job experience(s) aim to re-enter the labour market after the end of a temporary contract, the closure of the company, or other motivations, while those who aim to enter the labour market for the first time are mainly in the natural transition from school to work.

Our proposal is to provide knowledge for entrepreneurs and policymakers on: (1) how unemployed individuals look for a job, in terms of their multichannel attitude; (2) how they are characterised in terms of their choice of job-search channel(s); and (3) the differences (if any) between unemployed individuals with and without previous job experience. To shed light on these points, we use microdata from the LFS collected by ISTAT for the 2014-2018 period.

Firstly, we explore the determinants of the number of channels used by unemployed individuals when searching for a job by estimating a Poisson regression. As a limit of this analysis, we are not able to detect the features underlying the choice of each channel as well as the possible dependence structure between the job-search channels. We thereby specify a multivariate probit model that allows taking into account observable variables (e.g. socio-demographics) and unobservables (e.g., motivation, self-control, and preference, which are hardly measurable and not measured in the survey used). Specifically, the impacts of unobservables are estimated through the correlated error structure among utility functions of the different search channels. The main findings are the following.

We do not find important differences in the determinants in common between unemployed individuals with and without previous job experience. The only main difference is represented by the life-cycle phase. Trivially, unemployed individuals without previous job experience are mainly young and in the transition from school to work. Of interest, we find that the educational level achieved can shape the decision process of job searches using a multichannel approach. As compared to individuals who achieved upper secondary 
education, better-educated unemployed individuals, both with and without previous job experience, have a higher preference for using the internet and direct contact with firms rather than informal network channels. An opposite result is instead observed for individuals who achieved a lower educational level. Our findings also suggest how a better education may "protect" unemployed individuals who reside in the southern areas of Italy (which are characterised by higher unemployment rates than northern areas of the country) from discouragement behaviour in their job-search attitude.

For unemployed individuals with previous job experience, the characteristics of the last job play a crucial role in influencing the choice of channel(s) used to search for the next one. Unemployed individuals from highly skilled professions (e.g., intellectual, scientific, and high-specialisation professions, legislators, entrepreneurs, managers) consider fewer channels when searching for a job than other professions and hold a preference for the internet, while those from low-skill professions (e.g., fixed and mobile machinery workers, vehicle drivers, and non-qualified professions) have a higher probability of using agencies compared to other channels, especially in the first months after the loss of a job. The unemployed with office-worker experience, instead, have a higher multichannel attitude than the reference category (qualified professions in commercial activities and services) and have a higher probability of choosing the internet over other channels.

We also assume the presence of unobservables that are represented by features of the personality of an individual (such as motivation, self-control, and preference), which may affect the decision process and attitude towards a multichannel job search. These unobservables are hardly measurable and not measured in the survey used; they are captured in the estimation of model (5) through the correlated error structure among utility functions of the different search channels. A strong, positive, and significant correlation is found between job searching through the internet and through direct contact with firms, but with some spatial differences between macro-areas of the country. For instance, we find that these coefficients decrease in magnitude in north-eastern and central Italy. This suggests that in these macro-areas, the unobservable confounders contribute less to increasing the probability that unemployed persons search via the internet and through direct contact with firms than in other areas of the country. The application of the likelihood ratio test to the estimated pairwise correlation coefficients supports the importance of jointly estimating the equations representing each job-search channel considered in our analysis.

Evidence emerging from our analysis may help to improve knowledge of the multichannel job-searching behaviour of unemployed people for both employers (firms) who aim to hire employees and for policymakers aiming to design effective support services for jobsearch guidance.

From the employer or demand side, our analysis sheds light on the types of channels to activate/invest in to attract specific kinds of candidates. Drawing on our findings, we argue that firms/employers interested in young workers (unemployed without job experience) with high levels of education should favour the internet as a channel for advertising job vacancies, as well as direct contact. If they are instead interested in individuals with job experience, firms must differentiate their placement strategy according to the level of skills required. For highly skilled professions, the internet is the most common job-search channel, while for low-skilled professions, they should use agencies to advertise vacancies.

From the policymaker side, our results suggest including in the policy agenda certain action-strategies aimed at supporting or orientating the unemployed in their choice of jobsearch channels. These support services should consider both the observed and unobserved factors explored in our analysis. As regards the observed factors, education is among the most important. Education plays a relevant role in meeting the requirements of the labour market 
by providing useful skills for the use of new technologies, for automating new tasks, and for re-qualifying the tasks already in place (Mariani et al. 2020). The policy debate recognises the role of education in contributing to the reduction of risks that an unemployed person can encounter in the labour market, such as the vulnerability (especially among young unemployed individuals) to business-cycle and labour-market fluctuations (e.g. Zanin 2014; Struffolino and Raitano 2020). Our findings add material highlighting the importance of education also for job-search behaviours. In this regard, it has emerged that it is not only important to invest in education early in the educational path, but also in the supply of life-long learning services (e.g. for older unemployed individuals and/or those with a low level of education, to reduce possible barriers to (re-)entry into the labour market), as well as orientation in the job search, in order to help expose the unemployed to more job offer opportunities by encouraging them to use a multichannel approach. As regards the unobserved factors, policies may include support services for motivation, self-control, and preference through experts in psychology and the psychology of work and organisations (e.g. Woods and West 2010). These policies are crucial in an economic scenario in continuous evolution and characterised by new technological developments, in which firms require updated professional profiles to support their business activities in a competitive market.

Future research might address the assessment of changes (if any) in the (multichannel) jobsearching behaviour of the unemployed during and after the COVID-19 pandemic. This is because rules on social distancing put in place to prevent the spread of the virus might have contributed to increasing the preference for digital channels rather than physical ones (such as agencies). In addition, it might be interesting to expand the analysis to the behaviour of entrepreneurs searching for new employees and to highlight possible differences in behaviour (if present) when searching for an unemployed individual with or without previous job experience.

Acknowledgements We would like to thank the two anonymous reviewers for their constructive suggestions, which helped to improve the presentation and quality of the article. The opinions expressed herein are those of the authors and do not reflect those of the institutions of affiliation.

Funding This research has not received funding.

\section{Compliance with ethical standards}

Conflict of interest The authors declare that they have no conflict of interest.

\section{Appendix 1}

See Table 7. 
Table 7 Items used in the LFS questionnaires during the 1977-2018 period to collect information on jobsearch channels

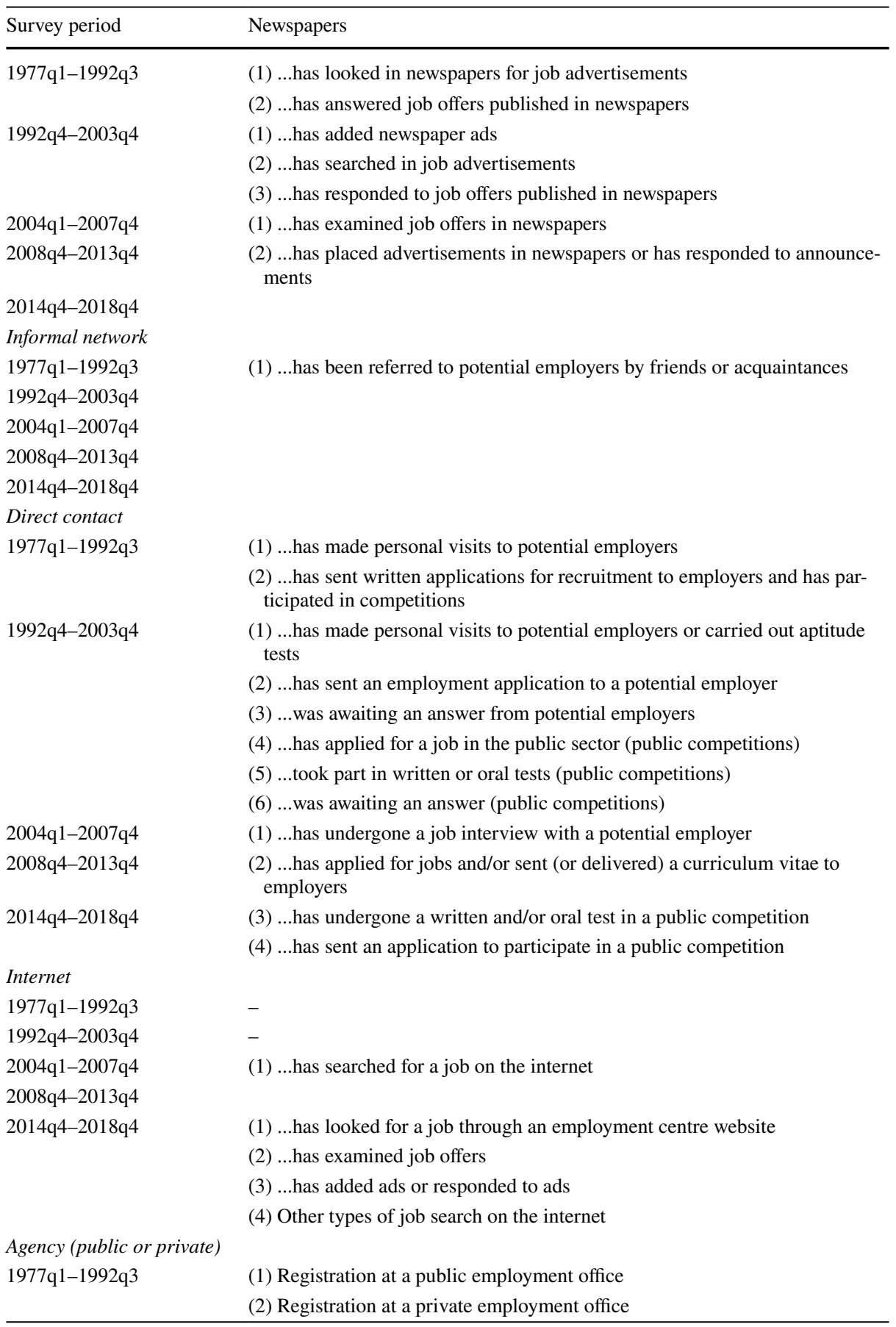


Table 7 (continued)

\begin{tabular}{ll}
\hline Survey period & Newspapers \\
\hline $1992 q 4-2003 q 4$ & (1) ...has visited a private employment agency \\
& (2) ...has provided an initial registration to a private employment agency \\
& (3) ... was informed about any job offers \\
$2004 q 1-2007 q 4$ & (4) ...is awaiting a call (public placement) \\
$2008 q 4-2013 q 4$ & (1) ...has had contact with a private employment agency or temporary agency \\
$2014 q 4-2018 q 4$ & (2) ...has had contact with a public employment centre \\
\hline
\end{tabular}

\section{Appendix 2}

\section{Evolution of Multichannel Job-Search Attitudes Among Unemployed Individuals in Italy: 1978-2018}

See Figs. 3, 4.

\section{Changes in the Italian LFS}

The LFS from ISTAT provides quarterly microdata since (the first quarter of) 1977. However, as mentioned in Sect. 3, the LFS has undergone important changes in its structure, frequency of data collection, definitions of the main labour market aggregates, and in the items used to collect information on job-search channels, which is the focus of our analysis. These changes do not allow comparability through time of the series of the main aggregates of the labour market and would require specific procedures of reconstruction of data to homogenise the information provided through time. Nonetheless, these changes/breaks were necessary to adapt and adjust the survey to the legislation introduced through time, as well as to allow comparability with the LFS of other European countries.

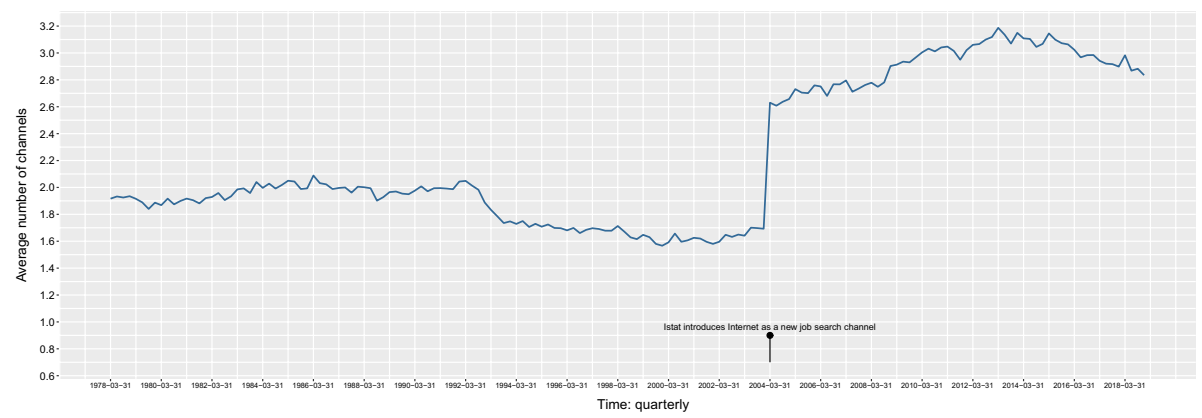

Fig. 3 Quarterly time series of the proxy of the multichannel attitude of an unemployed individual searching for a job during the 1978-2018 period 


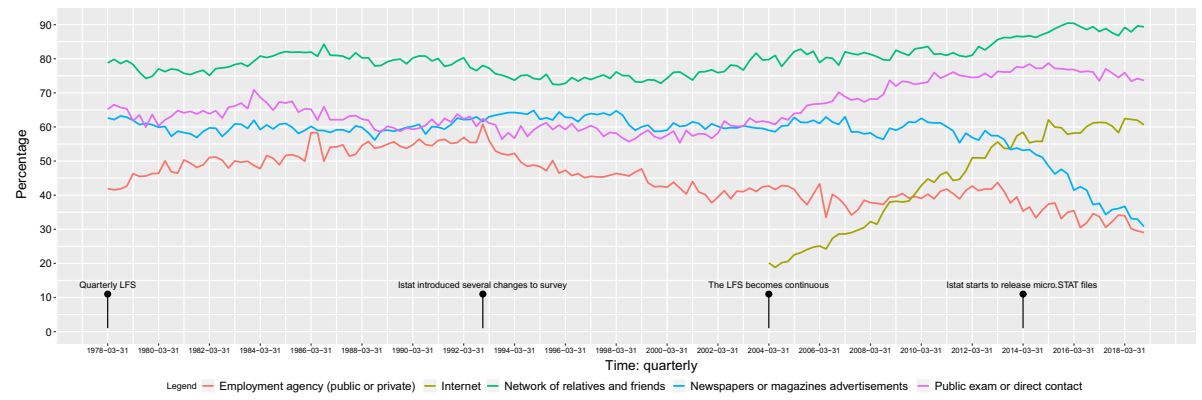

Fig. 4 Quarterly time series of the channels used by unemployed individuals who searched for a job during the 1978-2018 period

Table 7 offers a detailed list of the evolution of the items used to collect information on job-search channels in the questionnaires of the LFS during the 1977-2018 period. Figure 4 shows the quarterly time series of the channels used by unemployed individuals to search for a job during the period of 1978-2018, highlighting the most important changes in the LFS, according to the methodological notes provided by ISTAT. ${ }^{6}$ The dynamics of the aggregates examined were taken into account for the backward reconstruction process of the historical series.

The analysis here focuses on the period of 2014-2018 to avoid getting mixed up with the changes in the LFS and to ensure comparability of data and information. Moreover, since 2014, ISTAT started to release 'micro.STAT' files for free online. However, it is important to know and understand the changes that led to the current structure of the Italian LFS and, therefore, to the current set of items regarding job searches.

From Fig. 4, we note that in the data there were two main changes in the LFS, the first since the fourth quarter of 1992 and the second since the first quarter of 2004. These changes enforce data comparability only across the following three periods: 1977q1-1992q3; 1992q4-2003q4; and 2004q1 onwards.

During the first period, 1977q1-1992q3, the microdata, in addition to the variables originally defined, included some reconstructed variables to produce reliable estimates on the main labour market aggregates. In this period, the definitions of both employment and unemployment included individuals from 14 to 64 years of age.

The break/change introduced since the fourth quarter of 1992 was primarily due to the need to align the survey structure and definitions to the community legislation and included a new questionnaire, new items regarding job searches (see Table 7), and new definitions, especially for employed and unemployed individuals. From that period onwards, both of the definitions included individuals from 15 to 64 years of age (and not from 14 years of age, as previously) to allow comparability across European countries. Moreover, the estimates of the population were aligned to the 1981 census.

The new definitions and questionnaire were adopted through the period of 1992q4-2003q4. Since the first quarter of 2004, the survey changed both in the frequency of data collection and in its definitions and questionnaire. This break was motivated by the need to align the contents and characteristics of the LFS to European Community

6 Available online at https://www4.istat.it/it/archivio/206993. 
regulations (for instance, regulation No. 577/1998 in the Official Journal of the European Community).

The most important change was the frequency. The survey, which was quarterly, became continuous, with an increase in the frequency of data collection. Data also became available at a monthly frequency. The increased frequency increased the quality and precision of the estimates for the main labour market indicators. This was also ensured by changes introduced in the questionnaire and definitions. One of the most important changes in the questionnaire was the inclusion of the internet as a job-search channel. The effect of this additional channel on the intensity of the job search, as explained above, clearly emerges in Fig. 3.

Changes in the definitions mainly relate to employment and unemployment aggregates. The "employed" status started to be defined according to objective criteria, specifically, having worked one or more hours during the week preceding the survey. The definition of unemployed status instead extended the upper age limit to align the definitions with the regulations on retirement age, which in Italy continues to increase. The age brackets for unemployment were extended from 64 to 74 years of age.

\section{Appendix 3}

\section{Unemployed Individuals Without Previous Job Experience: Some Results from Estimated Model (5) for Each Macro-area}

See Tables 8, 9, 10, 11 and 12 .

\section{Unemployed Individuals with Previous Job Experience: Some Results from Estimated Model (5) for Each Macro-area}

See Tables 13, 14, 15, 16 and 17. 


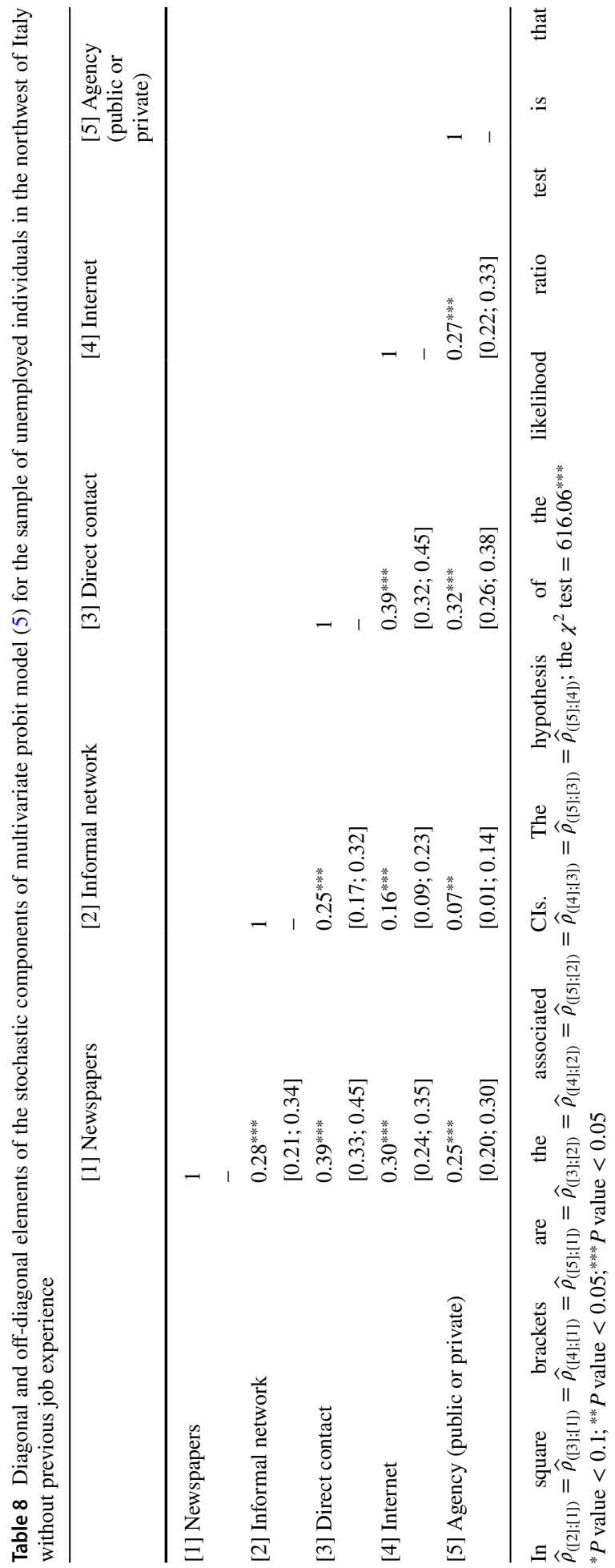




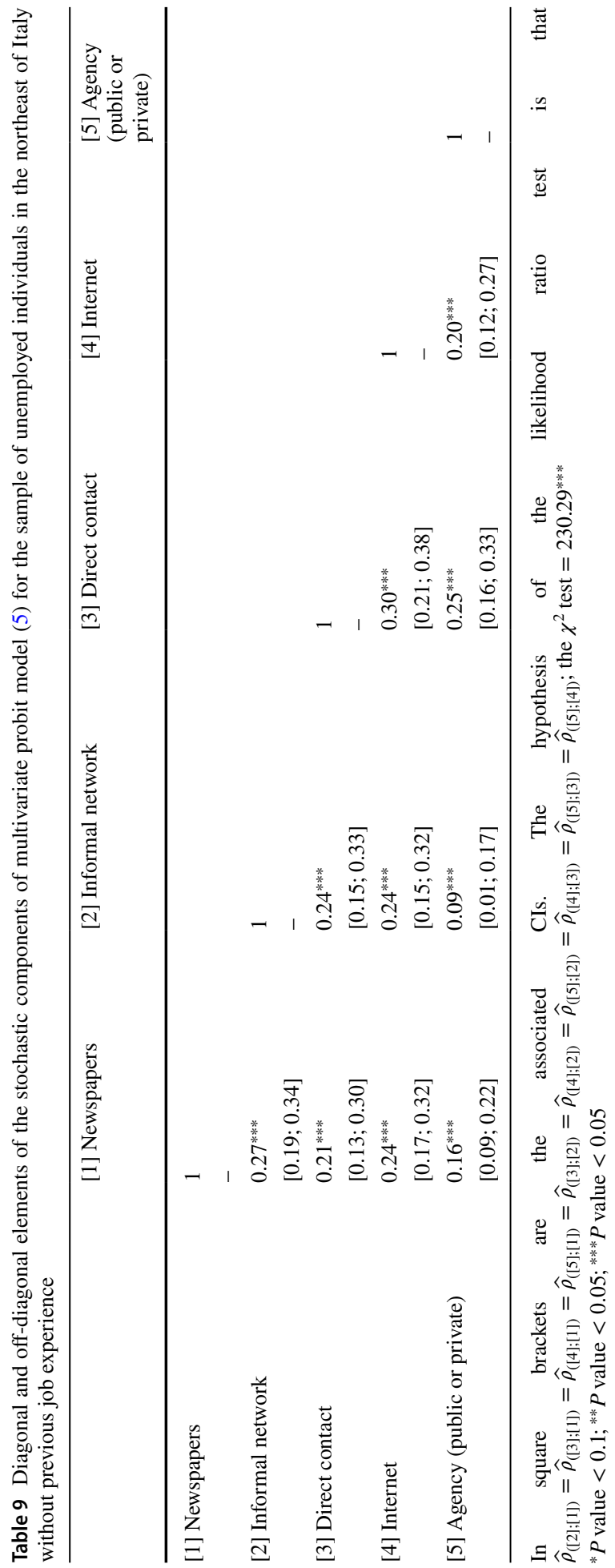




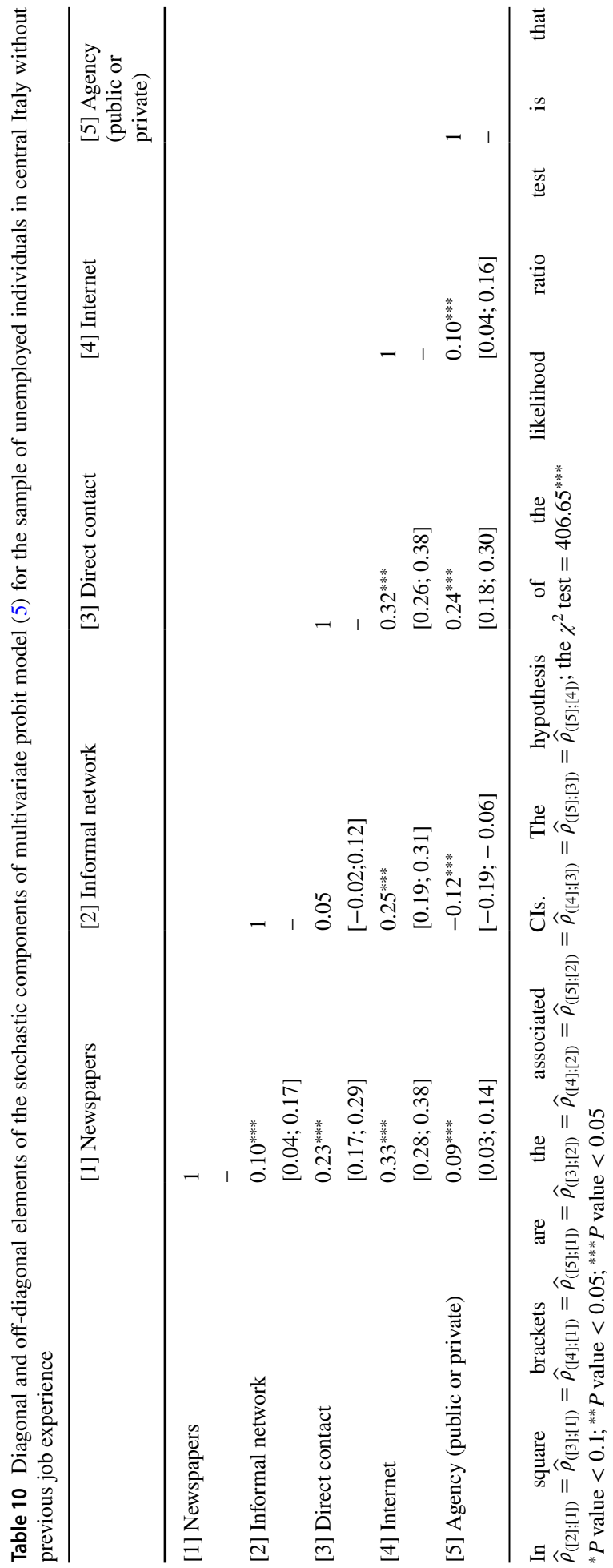




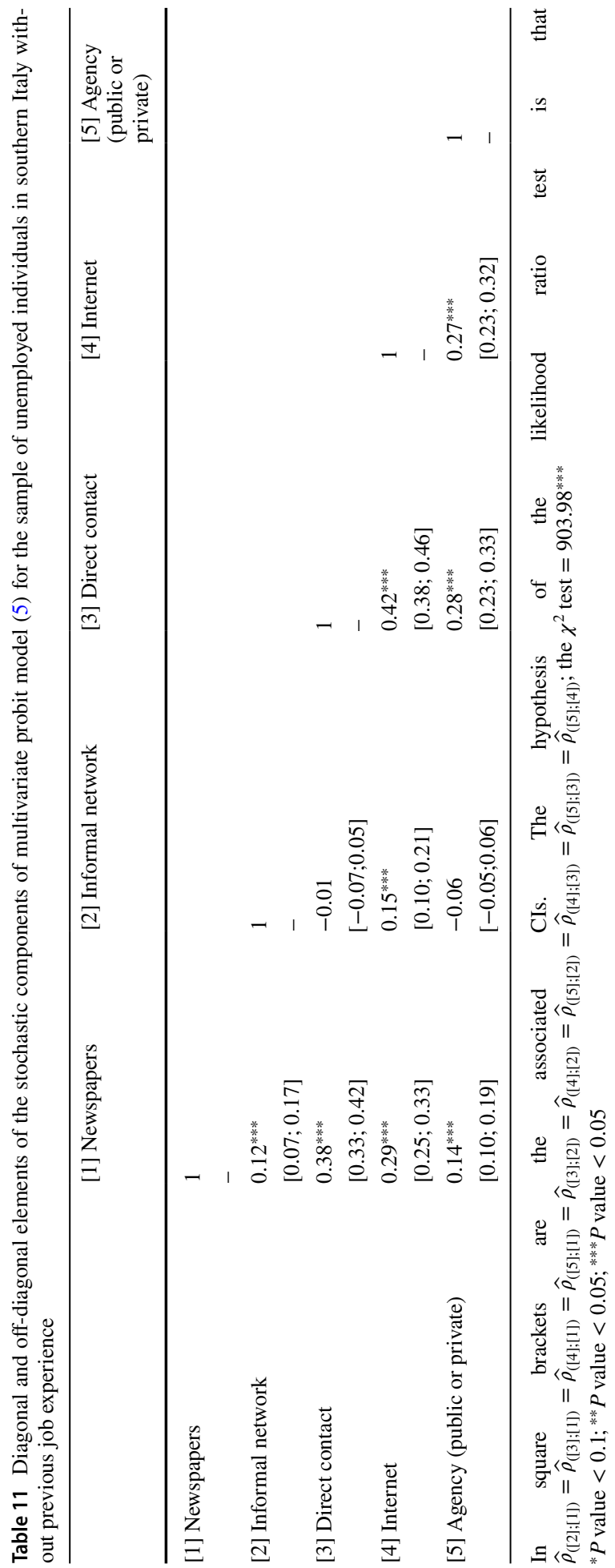




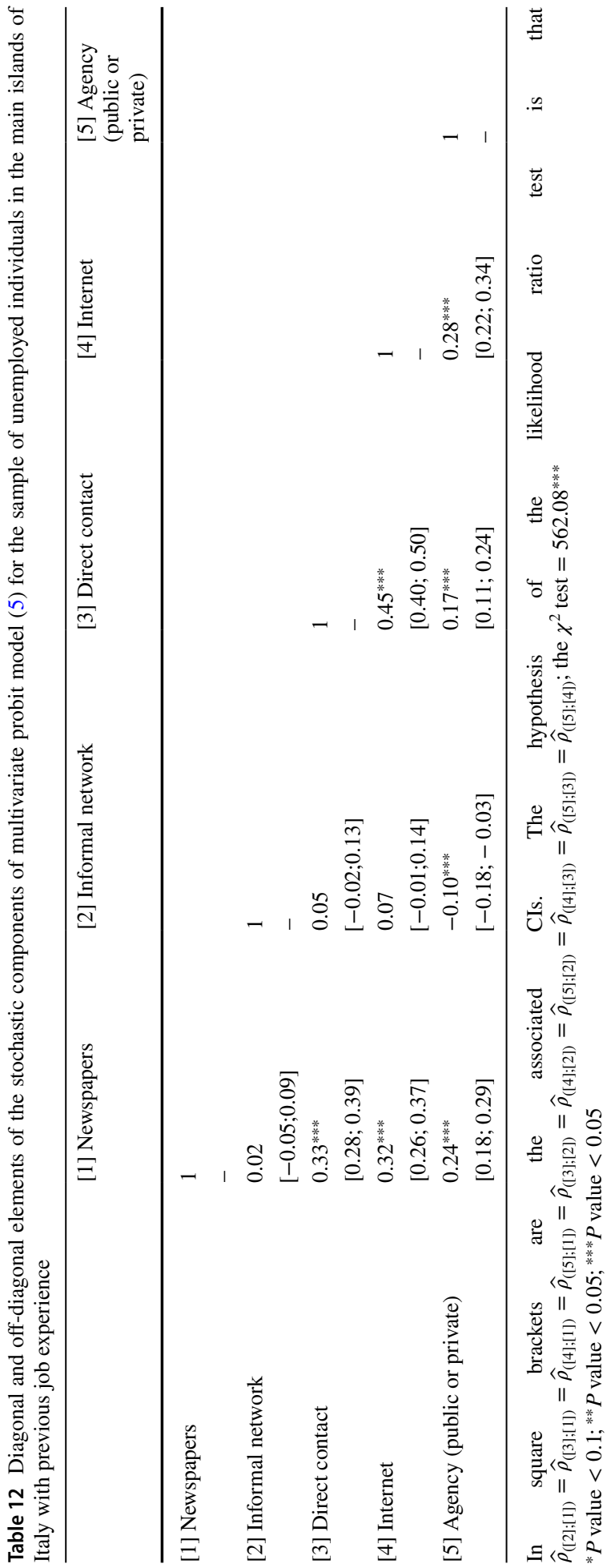




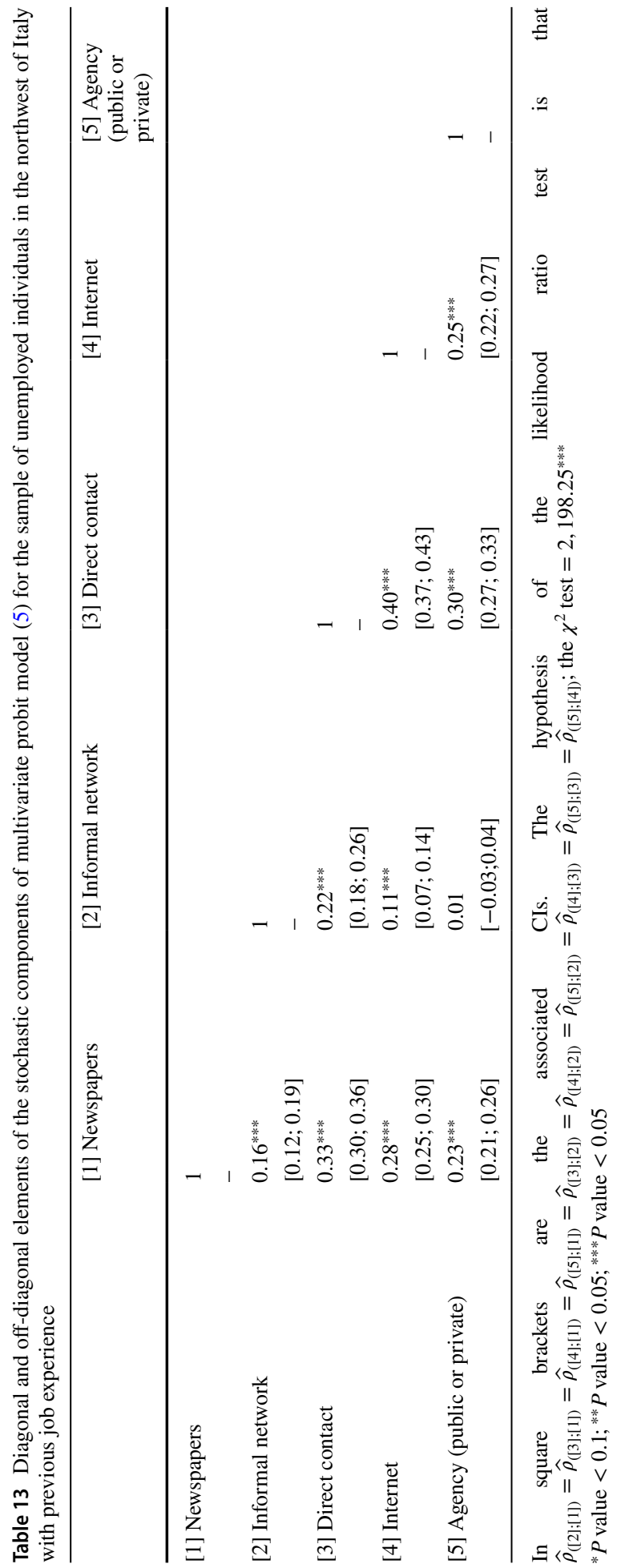




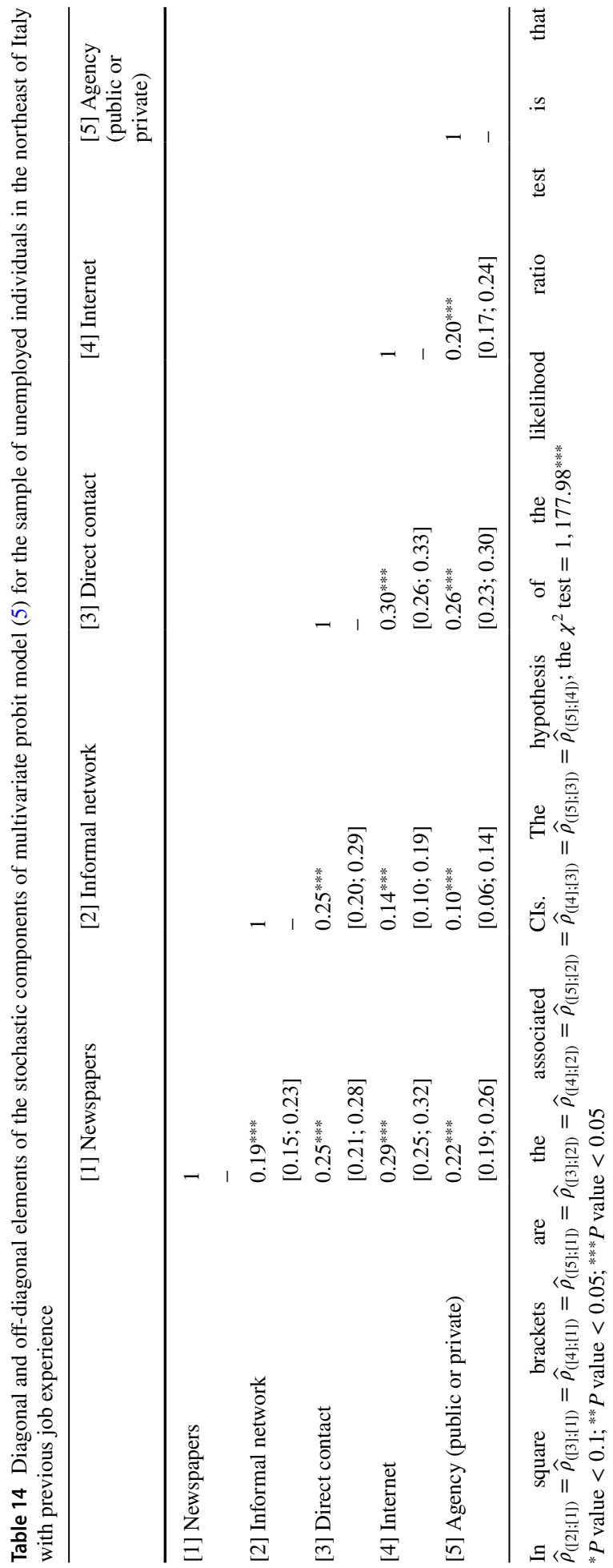




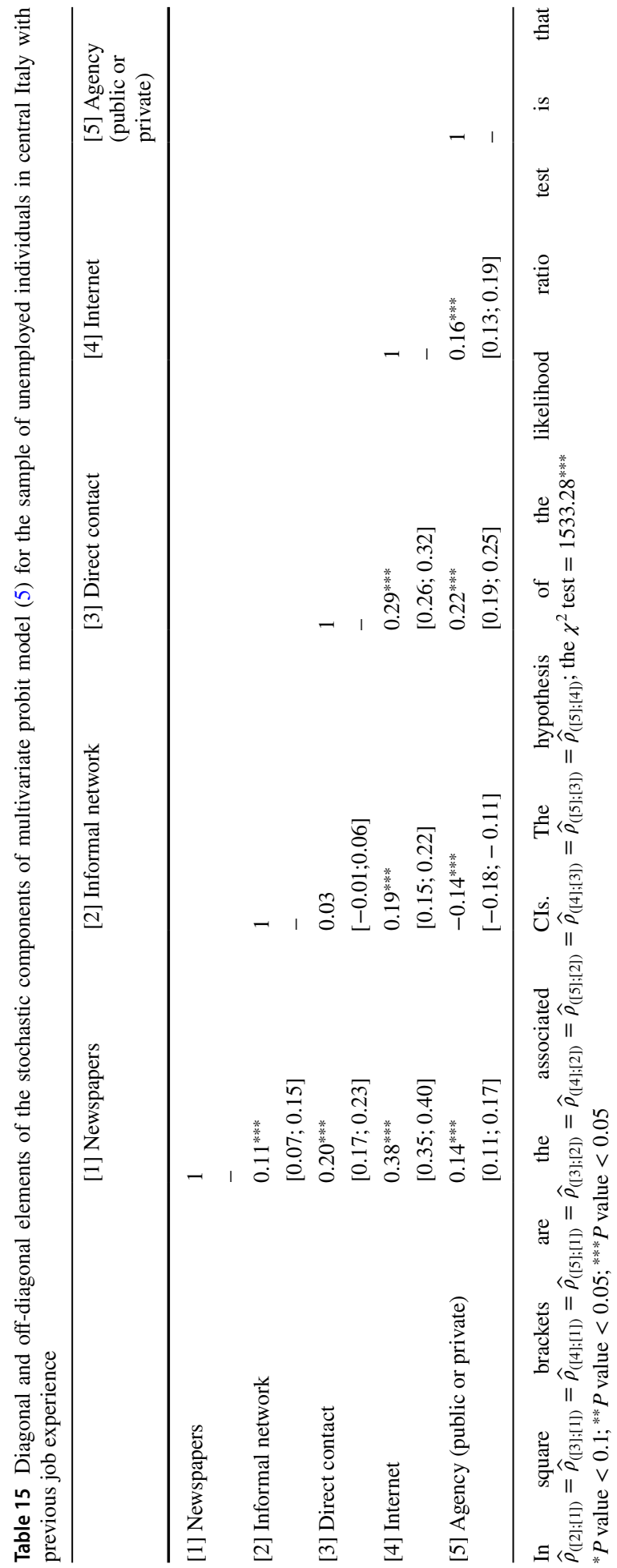




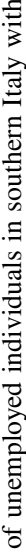

ชิ

营

$\stackrel{Ð}{\Xi}$

8

(2)

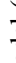

\%

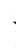

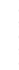

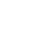

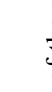




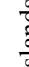

.

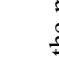

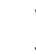

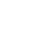

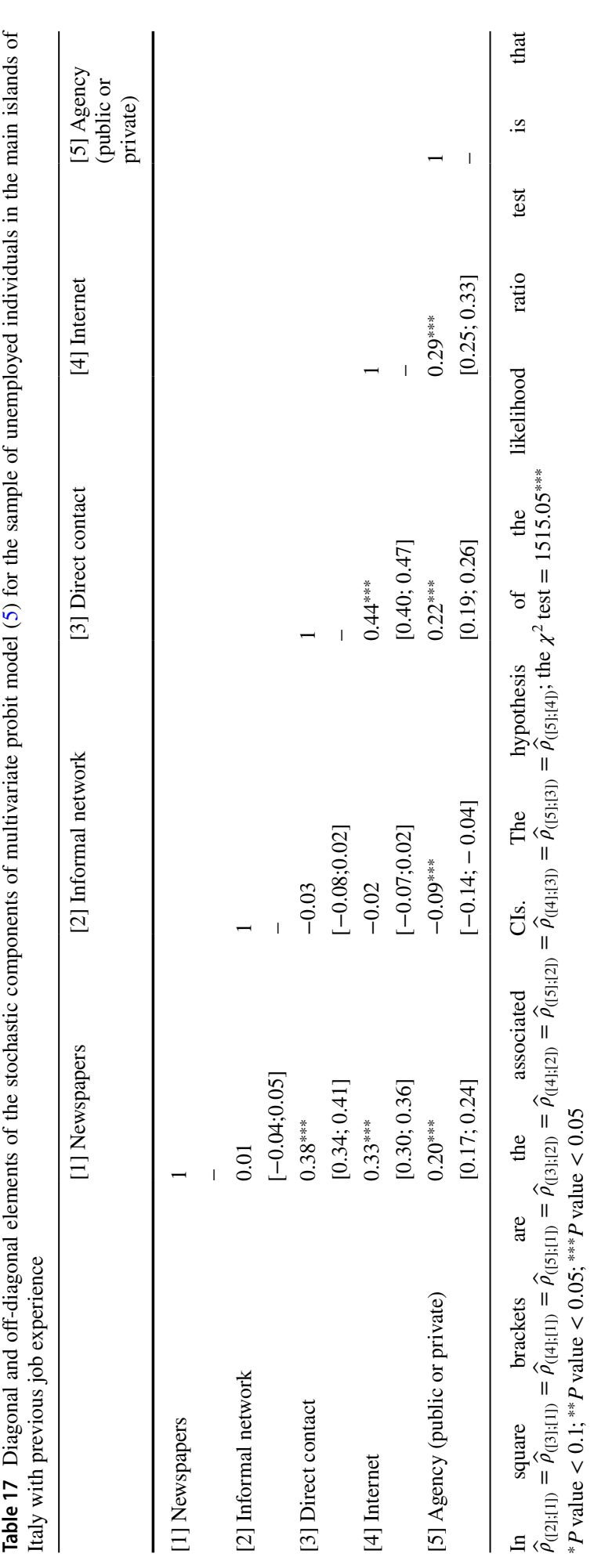




\section{References}

Acosta-Ballesteros, J., Osorno-del Rosal, Md, \& Rodríguez-Rodríguez, O. M. (2018). Overeducation of young workers in Spain: How much does the first job matter? Social Indicators Research, 138, $109-139$.

Adams, J., Greig, M., \& McQuaid, R. W. (2000). Mismatch unemployment and local labour-market efficiency: The role of employer and vacancy characteristics. Environment and Planning A: Economy and Space, 10, 1841-1856.

Addison, J. T., \& Portugal, P. (2002). Job search methods and outcomes. Oxford Economic Papers, 54, $505-533$.

Azmat, G., Guell, M., \& Manning, A. (2006). Gender gaps in unemployment rates in OECD countries. Journal of Labour Economics, 24(1), 1-37.

Baay, P. E., de Ridder, D. T. D., Eccles, J. S., van der Lippe, T., \& van Aken, M. A. G. (2014). Self-control trumps work motivation in predicting job search behavior. Journal of Vocational Behavior, 85, $443-451$.

Bachmann, R., \& Baumgarten, D. (2013). How do the unemployment search for a job? Evidence from the EU Labour Force Survey. IZA Journal of European Labor Studies, 2, 22.

Bandiera, O., Barankay, I., \& Rasul, I. (2007). Incentives for managers and inequality among workers: Evidence from a firm-level experiment. Quarterly Journal of Economics, 122, 729-773.

Barbieri, L., \& Mussida, C. (2018). Structural differences across macroregions: An empirical investigation. Empirica-Journal of European Economics, 45, 215-246.

Barron, J. M., Black, D. A., \& Loewenstein, M. A. (1989). Job matching and on-the-job training. Journal of Labor Economics, 7(1), 1-19.

Baussola, M. L., \& Mussida, C. (2017). Regional and gender differentials in the persistence of unemployment in Europe. International Review of Applied Economics, 31, 173-190.

Baussola, M. L., Mussida, C., Jenkins, J., \& Penfold, M. (2015). Determinants of the unemployment gender gap: A comparative investigation. International Labour Review, 154(4), 537-562.

Becker, H., Loder, A., Schmid, B., \& Axhausen, K. W. (2017). Modeling car-sharing membership as a mobility tool: A multivariate probit approach with latent variables. Travel Behaviour and Society, $8,26-36$.

Bejaković, P., \& Mrnjavac, Z. (2018). The danger of long-term unemployment and measures for its reduction: The case of Croatia. Economic Research-Ekonomska Istraživanja, 31, 1837-1850.

Bewley, T. (1999). Fairness, reciprocity, and wage rigidity. Cowles Foundation discussion paper no. 1383.

Blanchard, O., \& Jimeno, J. F. (1995). Structural unemployment: Spain versus Portugal. American Economic Review, 85(2), 212-218.

Blau, D. M., \& Robins, P. K. (1990). Job search outcomes for the employed and unemployed. Journal of Political Economy, 3, 637-655.

Brueckner, J. K., \& Zenou, Y. (2003). Space and unemployment: The labor-market effects of spatial mismatch. Journal of Labor Economics, 21, 242-262.

Calabrese, R., Osmetti, A. S., \& Zanin, L. (2019). A joint scoring model for peer-to-peer and traditional lending: A bivariate model with copula dependence. Journal of the Royal Statistical Society, Series A, 182, 1117-1665.

Caliendo, M., Schmidl, R., \& Uhlendorff, A. (2011). Social networks, job search methods and reservation wages: Evidence for Germany. International Journal of Manpower, 32(7), 796-824.

Cappellari, L., \& Tatsiramos, K. (2010). Friends' networks and job finding rates. CESifo working paper series, 3243, CESifo Group Munich.

Cappellari, L., \& Jenkins, S. P. (2003). Multivariate probit regression using simulated maximum likelihood. The Stata Journal, 3, 278-294.

Cappellari, L., \& Tatsiramos, K. (2015). With a little help from my friends? Quality of social networks, job finding rates and job match quality. European Economic Review, 78, 55-75.

Constant, A. F., Krause, A., Rinne, U., \& Zimmermann, K. F. (2011). Economic preferences and attitudes of the unemployed: Are natives and second generation migrants alike? International Journal of Manpower, 32, 825-851.

Cracolici, M. F., Cuffaro, M., \& Nijkamp, P. (2009). A spatial analysis on Italian unemployment differences. Statistical Methods and Applications, 18, 275-291.

de la Rica, S., \& Rebollo-Sanz, Y. F. (2015). Gender differentials in unemployment ins and outs during the great recession in Spain. IZA discussion paper, Vol. 9135. Bonn, Germany. 
De Paola, M., Ponzo, M., \& Scoppa, V. (2015). Gender differences in attitudes towards competition: Evidence from the Italian scientific qualification. CSEF working papers 391, Centre for Studies in Economics and Finance (CSEF), University of Naples, Italy.

Della Vigna, S., \& Paserman, M. D. (2005). Job search and impatience. Journal of Labor Economics, $23,527-588$.

Espasandín-Domínguez, J., Cadarso-Suárez, C., Kneib, T., Marra, G., Klein, N., Radice, R., et al. (2019). Assessing the relationship between markers of glycemic control through flexible copula regression models. Statistics in Medicine, 38, 5161-5181.

Fouarge, D., Schils, T., \& de Grip, A. (2013). Why do low-educated workers invest less in further training? Applied Economics, 45, 2587-2601.

Gai, Y., Feng, L., \& Hao, J. (2017). Local labor market condition and influenza vaccination. Atlantic Economic Journal, 45, 181-199.

Gimbel, M. E., \& Sinclair, T. M. (2020). Mismatch in online job search. Institute for International Economic Policy working paper series, IIEP-WP-2020-1.

Granovetter, M. S. (1973). The strength of weak ties. American Journal of Sociology, 78, 1360-1380.

Greene, W. (2012). Econometric Analysis (7th ed.). Upper Saddle River: Prentice Hall.

Hamilton, J. D. (2018). Why you should never use the Hodrick-Prescott filter. Review of Economics and Statistics, 100(5), 831-843.

Holzer, H. J. (1988). Search method use by unemployed youth. Journal of Labor Economics, 6(1), 1-20.

Ingold, J., \& Valizade, D. (2017). Employers' recruitment of disadvantaged groups: Exploring the effect of active labour market programme agencies as labour market intermediaries. Human Resource Management Journal, 27, 530-547.

International Labour Organization (ILO). (1982). Resolution concerning statistics of the economically active population, employment, unemployment and underemployment. In Thirteenth international conference of labour statisticians, Geneva, October 1982.

Ioannides, M., \& Loury, L. (2004). Job information networks, neighbourhood effects, and inequality. Journal of Economic Literature, 42, 1056-1093.

Kiefer, N. M. (1982). Testing for dependence in multivariate probit models. Biometrika, 69, 161-166.

Klehe, U.-C., \& van Hooft, E. (2018). The Oxford handbook of job loss and job search. New York: Oxford University Press.

Kramarz, F., \& Nordstrom Skans, O. (2007). Nepotism at work? Family networks and youth labor market entry. CREST working paper.

Kramarz, F., \& Nordstrom Skans, O. (2014). When strong ties are strong: Networks and youth labour market entry. Review of Economic Studies, 81, 1164-1200.

Krueger, A. B., \& Mueller, A. (2010). Job search and unemployment insurance: New evidence from time use data. Journal of Public Economics, 94, 298-307.

Labini, S. M. (2005). Job search methods and outcomes for the employed and unemployed: An empirical investigation. Pisa: Mimeo, Sant'Anna School of Advanced Studies.

Liechti, F. (2019). Connecting employers and workers: Can recommendations form the public employment service act as a substitute for social contacts? Work, Employment and Society. https://doi. org/10.1177/0950017019836888.

Mariani, P., Marletta, A., Mussini, M., \& Zenga, M. (2020). Professional profiles and job requirements in labour demand: An analysis of the Italian information technology sector. Social Indicators Research. https://doi.org/10.1007/s11205-020-02394-9.

Meliciani, V., \& Radicchia, D. (2011). The informal recruitment channel and the quality of job-worker matches: An analysis on Italian survey data. Industrial and Corporate Change, 20(2), 511-554.

Mortensen, D. T., \& Vishwanath, T. (1995). Personal contacts and earnings: It is who you know!. Labour Economics, 2(1), 103-4.

Mosca, M., \& Pastore, F. (2009). Wage effects of recruitment methods: The case of the Italian social service sector. In M. Musella \& S. Destefanis (Eds.), Paid and unpaid labour in the social economy. AIEL series in labour economics. Heidelberg: Physica.

Murtin, F., \& Robin, J. M. (2018). Labor market reforms and unemployment dynamics. Labour Economics, 50, 3-19.

Mussida, C., \& Zanin, L. (2020). I found a better job opportunity! Voluntary job mobility of employees and temporary contracts before and after the great recession in France, Italy and Spain. Empirical Economics, 59, 47-98.

Ochsen, C., \& Welsch, H. (2011). The social costs of unemployment: Accounting for unemployment duration. Applied Economics, Taylor and Francis Journals, 43(27), 3999-4005.

Pellizzari, M. (2010). Do friends and relatives really help in getting a good job? Industrial and Labor Relations Review, 63(3), 494-510. 
Perez-Gonzalez, F. (2006). Inherited control and firm performance. American Economic Review, 96(5), 1559-1588.

Petrongolo, B., \& Pissarides, C. A. (2001). Looking into the black box: A survey of the matching function. Journal of Economic Literature, 39(2), 390-431.

Pichler, F., \& Wallace, C. (2007). Patterns of formal and informal social capital in Europe. European Sociological Review, 23, 423-435.

Pissarides, C. A. (2000). Equilibrium unemployment theory (2nd ed.). Cambridge: MIT Press.

Pistaferri, L. (1999). Informal networks in the italian labor market. Giornale degli Economisti e Annali di Economia, Nuova Serie, 58(3/4), 355-375.

Ponzo, M., \& Scoppa, V. (2010). The use of informal networks in Italy: Efficiency of favoritism? Journal of Behavioral and Experimental Economics, 39(1), 89-99.

Putnam, R. D. (2000). Bowling alone: The collapse and revival of American community. New York: Simon $\&$ Schuster.

Radice, R., Zanin, L., \& Marra, G. (2013). On the effect of obesity on employment in the presence of observed and unobserved confounding. Statistica Neerlandica, 67, 436-455.

Ramia, G., Peterie, M., Patulny, R., \& Marston, G. (2020). Networks, case managers, and the job-search experiences of unemployed people. Social Policy and Administration. https://doi.org/10.1111/ spol.12575.

Santos Silva, J. M. C., \& Tenreyro, S. (2010). On the existence of the maximum likelihood estimates in Poisson regression. Economics Letters, 107, 310-312.

Santos Silva, J. M. C., \& Tenreyro, S. (2011). Further simulation evidence on the performance of the Poisson pseudo-maximum likelihood estimator. Economics Letters, 112, 220-222.

Struffolino, E., \& Raitano, M. (2020). Early-career complexity before and after labour market deregulation in Italy: Heterogeneity by gender and socio-economic status across cohorts. Social Indicators Research. https://doi.org/10.1007/s11205-020-02373-0.

Taylor, J., \& Bradley, S. (1997). Unemployment in Europe: A comparative analysis of regional disparities in Germany, Italy and the UK. Kyklos, 50(2), 221-245.

Torugsa, N., Yawised, K., \& O’Donohue, W. (2019). Social customer relationship management in small and medium enterprises: Overcoming barriers to success. In C. Machado \& J. Davim (Eds.), Management science. Management and industrial engineering. New York: Springer.

Tso, G. K. F., Yau, K. K. W., \& Cheung, M. S. M. (2010). Latent constructs determining Internet job search behaviors: Motivation, opportunity and job change intention. Computers in Human Behavior, 26, $122-131$.

Tutz, G. (2012). Regression for categorical data. New York: Cambridge University Press.

van den Berg, G. J., \& van der Klaauw, B. (2006). Counseling and monitoring of unemployed workers: Theory and evidence form a controlled social experiment. International Economic Review, 47(3), 895-936.

Van der Klaauw, B., \& Van Vuuren, A. (2010). Job search and academic achievement. European Economic Review, 54, 294-316.

van Huizen, T., \& Plantenga, J. (2014). Job search behaviour and time preferences: Testing exponential versus hyperbolic discounting. De Economist, 162, 223-245.

Vansteenkiste, M., Lens, W., De Witte, S., De Witte, H., \& Deci, E. L. (2004). The 'Why' and 'Why not' of job search behaviour: Their relation to searching unemployment experience, and well-being. European Journal of Social Psychology, 34, 345-363.

Weber, A., \& Mahringer, H. (2008). Choice and success of job search methods. Empirical Economics, 35, $153-178$.

Winkelmann, R. (2012). Copula bivariate probit models: With an application to medical expenditures. Health Economics, 21, 1444-1455.

Woods, S. A., \& West, M. A. (2010). The psychology of work and organizations. Cengage learning EMEA. Singapore: Seng Lee Press.

Zanin, L. (2013). Detecting unobserved heterogeneity in the relationship between subjective well-being and satisfaction in various domains of life using the REBUS-PLS path modelling approach: a case study. Social Indicators Research, 110(1), 281-04.

Zanin, L. (2015). Exploring the effect of participation in sports on the risk of overweight. Applied Research Quality Life, 10, 381-404.

Zanin, L. (2016). On Italian households' economic inadequacy using quali-quantitative measures. Social Indicators Research, 128(1), 59-88.

Zanin, L. (2017). Determinants of the conditional probability that a household has informal loans given liquidity constraints regarding access to credit banking channels. Journal of Behavioral and Experimental Finance, 13, 16-24. 
Zanin, L. (2018). The pyramid of Okun's coefficient for Italy. Empirica-Journal of European Economics, $45,17-28$

Zanin, L. (2018). Private monetary transfers between households: Who is helped and by whom? Journal of Behavioral and Experimental Finance, 17, 76-82.

Zanin, L., \& Calabrese, R. (2017). Interaction effects of region-level GDP per capita and age on labour market transition rates in Italy. IZA Journal of Labor Economics, 6, 4.

Zanin, L., Radice, R., \& Marra, G. (2013). Estimating the effect of perceived risk of crime on social trust in the presence of endogeneity bias. Social Indicators Research, 114, 523-547.

Zikic, J., \& Saks, A. M. (2009). Job search and social cognitive theory: The role of career-relevant activities. Journal of Vocational Behavior, 74, 117-127.

Publisher's Note Springer Nature remains neutral with regard to jurisdictional claims in published maps and institutional affiliations. 